\title{
Advanced Nanocomposite Coatings of Fusion Bonded Epoxy Reinforced with Amino-Functionalized Nanoparticles for Applications in Underwater Oil Pipelines
}

\author{
Patricia A. Saliba, Alexandra A. P. Mansur, and Herman S. Mansur \\ Center of Nanoscience, Nanotechnology, and Innovation-CeNano ${ }^{2}$ I, Department of Metallurgical and Materials Engineering, \\ Federal University of Minas Gerais, Belo Horizonte, MG, Brazil \\ Correspondence should be addressed to Herman S. Mansur; hmansur@demet.ufmg.br
}

Received 7 August 2016; Accepted 3 October 2016

Academic Editor: Jim Low

Copyright (C) 2016 Patricia A. Saliba et al. This is an open access article distributed under the Creative Commons Attribution License, which permits unrestricted use, distribution, and reproduction in any medium, provided the original work is properly cited.

\begin{abstract}
The performance of fusion-bonded epoxy coatings can be improved through advanced composite coatings reinforced with nanomaterials. Hence, in this study a novel organic-inorganic nanocomposite finish was designed, synthesized, and characterized, achieved by adding $\gamma$-aminopropyltriethoxysilane modified silica nanoparticles produced via sol-gel process in epoxy-based powder. After the curing process of the coating reinforced with nanoparticles, the formation of a homogenous novel nanocomposite with the development of interfacial reactions between organic-inorganic and inorganic-inorganic components was observed. These hybrid nanostructures produced better integration between nanoparticles and epoxy matrix and improved mechanical properties that are expected to enhance the overall performance of the system against underwater corrosion.
\end{abstract}

\section{Introduction}

Nanotechnology is growing at a very rapid pace in practically all fields of science and technology such as materials engineering, biomedicine, mechanics, textiles, cosmetics, agriculture, food packaging, optoelectronic and semiconductor devices, aerospace, construction, catalysis, and dentistry. Essentially, it involves the design, synthesis, characterization, and application of materials, components, and devices on the nanometer scale, that is, at sizes below $100 \mathrm{~nm}$. At the nanoscale, physical, chemical, and biological properties significantly differ from the properties of individual atoms and molecules and from bulk matter, which accounted for the quantum confinement regime. Therefore, it provides a unique opportunity to develop new classes of materials, by tuning their properties and responses of living and nonliving matter, which should meet the challenges and requirements of advanced applications [1]. In the large field of nanotechnology, polymer matrix based nanocomposites have become a prominent area of current research and development $[1,2]$. Polymer-based (nano)composites have been intensively studied in recent decades, which are commonly made of organic polymer matrices mostly combined with inorganic fillers. Fundamentally, the composites aim at merging the beneficial properties of inorganic materials (e.g., thermal and mechanical stabilities) and of organic polymer (e.g., light weight, flexibility, ductility, and processability) for producing innovative materials with superior properties distinct from the pristine components [3]. But the main properties of the polymer-based composites are inherently affected by the volume fraction, dimensions, shapes, and morphological aspects of the inorganic fillers. Therefore, the incorporation of the nanosized inorganic components leads to a dramatic increase in the interfacial area, which assigns unique properties to the polymer nanocomposites as compared with the ordinary composites. Amongst several alternatives of polymers for producing nanocomposites, epoxies as thermosetting polymers have been widely used as coatings, adhesives, electronic devices packing, medical devices, optical components, and structural composites due to their superior properties and low cost. However, the intrinsic brittle nature of most high-performance epoxy 
polymers requires the incorporation of reinforcing agents for improving the toughness and other properties. Several strategies have been explored for improving the properties of (nano)composites including the incorporation of inorganic particles, rubber particles, fibers, glass beads, microvoids, hyperbranched polymers, thermoplastic particles, and combinations of these materials [4]. In that sense, nanosized silica particle is the most commonly used nanoparticle (NP) in the preparation of nanocomposites because of its set of advantageous properties [1]. Nowadays, silica nanoparticles in the forms of amorphous or crystalline possess innumerous applications as nanomaterials in the fields of catalysis, paint stabilization, food industry, electronics, and sensors. These nanoparticles can be used in combination with polymeric matrices forming composites for improving the thermal resistance and electrical and mechanical properties, enhancing the chemical stability and tribological properties. However, due to their very small dimensions, large surface area/volume ratio, and high surface free energy, nanoparticles tend to be agglomerated reducing their dispersion in the polymeric matrices and, therefore, affecting the overall properties of the nanocomposite [5]. Thus, many efforts have been exerted to overcome this problem and to improve interactions between NPs and different polymeric matrixes. For instance, the surface of silica nanoparticles can be modified in order to achieve an appropriate dispersion in the polymeric media, as well as better functionality. Grafting of silane coupling agents on the surface of silica nanoparticles to increase the mechanical properties of nanocomposites has been the subject of numerous investigations [1]. Depending on hydrophilic or hydrophobic nature of the silane coupling agent, the surface characteristics of the modified nanoparticles can be different. The hydrophilic nature of nanoparticles increases the surface energy and reduces its wettability by a polymeric matrix $[5,6]$.

Epoxy-based composite coatings are the oldest and still one of the largest classes of thermosetting powder coatings, which consists of a mixture of a primary resin (e.g., bisphenol-A diglycidyl ether, DGEBA), a crosslinker (e.g., polyamines), and in some cases, with the incorporation of inorganic fillers [7]. It is generally applied to the substrate, usually metal, and fused to a continuous film by baking, at temperatures in the range of $140-240^{\circ} \mathrm{C}$. The performance of protective coatings is frequently limited by durability of the metal/polymer interface under harsh environment (i.e., wet, corrosive, abrasive, etc.). Fusion bonded-epoxy (FBE) powder coatings, which were first developed by $3 \mathrm{M}$ Co., are broadly used as high-performance composite coatings when long-term corrosion protection and thermochemical stability are critical such as in the oil, metal, gas, and water pipelines industries [8-11]. This coating has proven to be a cost-effective material for increasing the service life of reinforced structures. Yet, the performance requirements for FBE powder coatings are challenging because of their high crosslinking density. The inherent brittleness of cured coatings is one of the major obstacles restricting several applications for epoxies in a broader range of industries. Therefore, many methods have been used for improving the toughness of composite epoxy systems, including introducing nanoscale reinforcements to these materials, a possible way to achieve improved mechanical properties.

However, surprisingly, although few papers have investigated the epoxy composite-steel interfacial properties $[9,12]$, no published report was found in consulted literature using a nanotechnology approach, where chemically modified silica nanoparticles were used as multifunctional nanoreinforcements for FBE epoxy powder coatings and the morphological and structural features were systematically characterized.

Hence, in this study, a novel organic-inorganic nanocomposite coating was designed, synthesized, and characterized, achieved by adding chemically modified silica nanoparticles (NPs) with $\gamma$-aminopropyltriethoxysilane (3-APTES) produced via sol-gel process into FBE epoxy powder, aiming at producing advanced nanocomposite coatings, which might lead to relevant improvements in performance for submarine steel oil pipelines.

\section{Materials and Methods}

2.1. Materials. Tetraethyl orthosilicate (TEOS, 98\%, $\left.\mathrm{Si}\left(\mathrm{OC}_{2} \mathrm{H}_{5}\right)_{4}\right)$, (3-aminopropyl)triethoxysilane (3-APTES, $\left.99 \%, \mathrm{H}_{2} \mathrm{~N}\left(\mathrm{CH}_{2}\right)_{3} \mathrm{Si}\left(\mathrm{OC}_{2} \mathrm{H}_{5}\right)_{3}\right)$, and ammonium hydroxide (28-30\%, $\left.\mathrm{NH}_{4} \mathrm{OH}\right)$ were purchased from Sigma Aldrich (USA). Ethanol $\left(99.5 \%, \mathrm{C}_{2} \mathrm{H}_{6} \mathrm{O}\right)$, potassium hydroxide $(85 \%$, $\mathrm{KOH})$, nitric acid (64-66\%, $\left.\mathrm{HNO}_{3}\right)$, and 2-propanol (99.5\%, $\left.\left(\mathrm{CH}_{3}\right)_{2} \mathrm{CHOH}\right)$ were obtained from Synth (Brazil). All chemicals and reagents were used as received without further purification. FBE powder (Scotchkote ${ }^{\mathrm{TM}} 226 \mathrm{~N}, 3 \mathrm{M}^{\mathrm{TM}}$, River Place Blvd., Austin, USA) was used as the coating material. Deionized (DI) water (Millipore Simplicity ${ }^{\mathrm{TM}}$ ) with resistivity of $18 \mathrm{M} \Omega \cdot \mathrm{cm}$ was used in the preparation of all solutions. All of the preparations and syntheses were performed at room temperature $\left(25 \pm 2^{\circ} \mathrm{C}\right)$ unless specified otherwise.

\subsection{Methods}

2.2.1. Syntheses of Bare Silica and Amino-Modified Silica Nanoparticles. In this work, the reaction of TEOS in ethanol in the presence of $\mathrm{NH}_{4} \mathrm{OH}$ as catalyst for the production of silica nanoparticles was used. The syntheses of silica nanoparticles and surface-functionalized silica nanoparticles with aminopropyl groups were performed based on a previous report by Capeletti et al. [13] with some modifications. In summary, in the case of bare silica nanoparticles, $538 \mu \mathrm{L}$ of TEOS was solubilized in $12.2 \mathrm{~mL}$ of ethanol under stirring. After $30 \mathrm{~min}, 400 \mu \mathrm{L}$ of $\mathrm{NH}_{4} \mathrm{OH}$ was added to the alcoholic TEOS solution. Then, the flask was tightly sealed and the stirring was maintained for $24 \mathrm{~h}$ at room temperature. The resulting material (referred to as $\mathrm{NanoSiO}_{2}$ ) was precipitated by centrifugation, washed 4 times by redispersion of the nanoparticles in $1 \mathrm{~mL}$ of ethanol using ultrasonic bath followed by centrifugation and removal of supernatant. In the sequence, nanoparticle precipitate was dried at room temperature for $48 \mathrm{~h}$ and grounded using mortar and pestle to remove the agglomeration. Analogously, the surfacemodified silica nanoparticles were prepared with the same procedure described above, with the addition of $283 \mu \mathrm{L}$ of 3-APTES in the flask with just synthesized silica colloidal 
TABLE 1: Concentrations and molar ratios of reagents and precursors used for the synthesis of silica-based nanoparticles.

\begin{tabular}{lcccccc}
\hline Sample & Reagent & TEOS & $\mathrm{H}_{2} \mathrm{O}$ & $\mathrm{NH}_{3}$ & EtOH & 3-APTES \\
\hline \multirow{2}{*}{$\mathrm{NanoSiO}_{2}$} & Concentration $\left(\mathrm{mol} \cdot \mathrm{L}^{-1}\right)$ & 0.18 & 1.21 & 0.36 & 15.59 & - \\
& Molar ratio & 1.0 & 6.7 & 2.0 & 86.6 & - \\
\multirow{2}{*}{$\mathrm{NanoSiO}_{2}$-APTES } & Concentration $\left(\mathrm{mol} \cdot \mathrm{L}^{-1}\right)$ & 0.18 & 1.21 & 0.36 & 15.59 & 0.09 \\
& Molar ratio & 1.0 & 6.7 & 2.0 & 86.6 & 0.5 \\
\hline
\end{tabular}

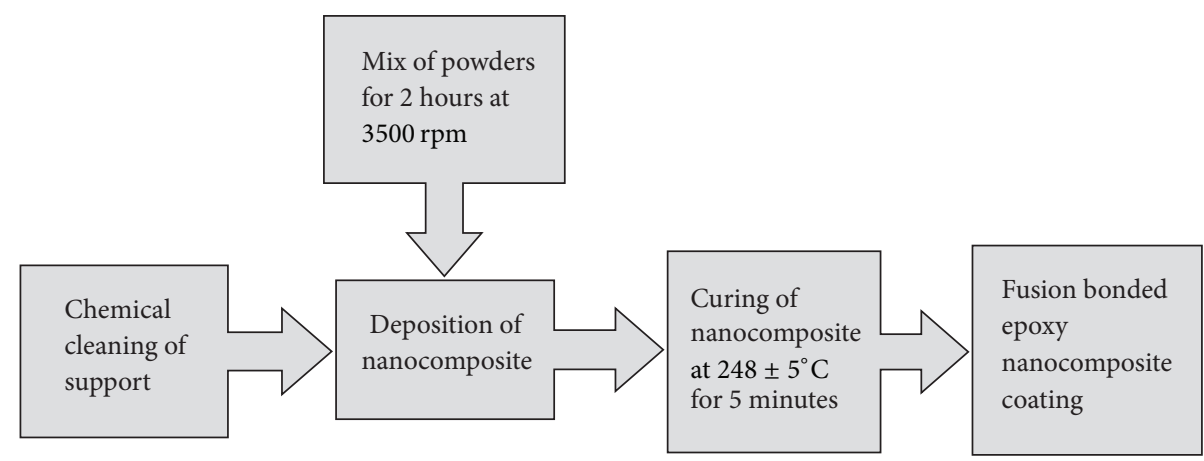

FIGURE 1: Schematic representation of the deposition and curing of the FBE nanocomposite coatings.

suspension. This dispersion was maintained under continuous stirring for additional $24 \mathrm{~h}$ at room temperature to perform the surface functionalization. Next, the dry powder of this nanomaterial (referred to as $\mathrm{NanoSiO}_{2}$-APTES) was obtained using the same procedure described for $\mathrm{NanoSiO}_{2}$ sample. The molar ratios (related to TEOS) of reagents and precursors are showed in Table 1. Before using the $\mathrm{SiO}_{2}$ nanofiller as reinforcement material, the nanoparticles were thermally treated at $200^{\circ} \mathrm{C}$ or $400^{\circ} \mathrm{C}$ for $2 \mathrm{~h}$ for the thermochemical stabilization and reduction of particles agglomeration.

2.2.2. Characterization of Bare Silica and Amino-Modified Silica Nanoparticles. The morphological features of the nanoparticles were characterized by scanning electron microscopy (SEM, FEI-INSPECTTM S50) coupled with energy dispersion X-ray spectroscopy (EDX, EDAX GENESIS) and transmission electron microscopy (TEM, Tecnai G2-20-FEI microscope, $200 \mathrm{kV}$ ). For SEM analysis, before examination, the samples were coated with a thin carbon film by sputtering using a low deposition rate, substrate cooling, and maximum distance between the target and sample in order to avoid sample damage. Images of secondary electrons (SE) were obtained with an accelerating voltage of $15 \mathrm{kV}$. The TEM samples were prepared by dropping an aliquot of ethanolic dispersion of nanoparticle samples $\left(0.5 \mathrm{~g} \mathrm{~L}^{-1}\right.$ ultrasonicated for $\left.30 \mathrm{~min}\right)$ onto a holey carbon grid before analysis. The nanoparticle size distributions were obtained from the SEM and TEM images by measuring at least 100 randomly selected nanoparticles using image processing program freeware (ImageJ, version 1.50).

Nanoparticles were analyzed by Diffuse Reflectance Infrared Fourier Transform Spectroscopy (DRIFTS) method (Thermo Fisher, Nicolet 6700) over the range of 400 to $4000 \mathrm{~cm}^{-1}$ using 64 scans and a resolution of $2 \mathrm{~cm}^{-1}$. The powder samples were mixed in a ratio of $1 \%$ (wt.\%) to potassium bromide (Sigma Aldrich, USA, $\geq 99 \%, \mathrm{KBr}$, suitable for spectroscopy) previously dried at $110 \pm 5^{\circ} \mathrm{C}$ for $2 \mathrm{~h}$.

Thermogravimetric (TG) and differential scanning calorimetry (DSC) thermal analyses were performed using SDT Q-600 simultaneous TGA/DSC instrument (TA Instruments Co., New Castle, DE, USA). Samples of approximately $6.5 \pm 1.0 \mathrm{mg}$ were used for the experiments at a heating rate of $10^{\circ} \mathrm{C} \cdot \mathrm{min}^{-1}$ (range from 20 to $900^{\circ} \mathrm{C}$ ). The samples were loaded into an open alumina crucible. TG and DSC curves were recorded simultaneously with $0.1 \mu \mathrm{g}$ sensitivity. The thermal analyses were performed under the continuous flow of dry nitrogen gas $\left(50 \mathrm{~mL} \cdot \mathrm{min}^{-1}\right)$.

Dynamic light scattering (DLS) measurements were performed on the colloidal suspension of nanoparticles in ethanol after the synthesis using a Brookhaven ZetaPlus instrument with a laser light wavelength of $660 \mathrm{~nm} \mathrm{(35}$ $\mathrm{mW}$ red diode laser) and a thermostat with temperature stabilization. Standard square quartz cells with a volume of $4.5 \mathrm{~mL}$ were used. Samples were measured at $25 \pm 2^{\circ} \mathrm{C}$ and light scattering was detected at $90^{\circ}$. Five measurements were obtained for each system and averaged.

2.2.3. Deposition and Characterization of Epoxy-Based Nanocomposite Coating Reinforced with Silica and SurfaceModified Nanoparticles. Epoxy-based FBE powder was mixed with $\mathrm{NanoSiO}_{2}$ or $\mathrm{NanoSiO}_{2}$-APTES nanoparticles (1\% wt.\%) previously synthesized and thermally stabilized. The powder mixtures were homogenized by mechanical stirring at $3500 \mathrm{rpm}$ for $2 \mathrm{~h}$. In the sequence, $\mathrm{FBE}$ powder and $\mathrm{FBE}$ reinforced with $\mathrm{SiO}_{2}$ nanoparticles (FBE-NanoSiO and FBE-NanoSiO 2 -APTES) were deposited on the solid support and the system was heated at $248 \pm 5^{\circ} \mathrm{C}$ for $5 \mathrm{~min}$ and cooled down to room temperature, as schematically represented in Figure 1. 
The morphology of the reference FBE coating and FBE nanocomposite coatings was evaluated using scanning electron microscopy (SEM), where images were taken from freshly freeze-fractured surfaces of glass slide/coating systems with a FEI-INSPECTTM S50 microscope coupled to EDX (EDAX GENESIS) for semiquantitative chemical analysis. Before examination, samples were sputtered with carbon as previously described. Images of secondary electrons (SE) and backscattered electrons (BSE) were obtained using an accelerating voltage of $15 \mathrm{kV}$.

Midinfrared spectroscopy (Thermo Fisher, Nicolet 6700) of FBE coatings was collected using attenuated total reflectance method (ATR, 4000 to $675 \mathrm{~cm}^{-1}, 32$ scans, and a $4 \mathrm{~cm}^{-1}$ resolution). In addition, Fourier transform infrared image mapping (FTIR-I) analysis of the cured coatings was performed using Nicolet-iN10 infrared microscope (Thermo Electron Corp., WI, USA) with OMNIC Picta software (Thermo Scientific, WI, USA). ATR image mappings were acquired between 4000 and $675 \mathrm{~cm}^{-1}$ with a spectral resolution of $8 \mathrm{~cm}^{-1}$. For each sample, an area of $400 \mu \mathrm{m}$ $\times 400 \mu \mathrm{m}$ was randomly selected for imaging and analysis constituting 441 points of spectral data acquisition per region analyzed.

DSC analyses were performed using SDT Q-600 instrument (TA Instruments Co) to verify the transition temperature $\left(T_{g}\right)$ of the cured coatings. About $6.0 \pm 1.0 \mathrm{mg}$ of FBE, FBE-NanoSiO 2 , and $\mathrm{FBE}-\mathrm{NanoSiO}_{2}$-APTES powders was submitted to the following thermal profile: 1st step: temperature increase at $10^{\circ} \mathrm{C} \cdot \mathrm{min}^{-1}$ from $25^{\circ} \mathrm{C}$ up to $300^{\circ} \mathrm{C}$; 2nd step: cooling down to room temperature; 3rd step: temperature increase at $10^{\circ} \mathrm{C} \cdot \mathrm{min}^{-1}$ from $25^{\circ} \mathrm{C}$ up to $300^{\circ} \mathrm{C}$. The experiments were carried out in aluminum crucibles with nonsealed lids under nitrogen gas flow of $50 \mathrm{~mL} \cdot \mathrm{min}^{-1}$. $T_{g}$ was calculated as the midpoint temperature according to ASTM E1356-08 (Standard Test Method for Assignment of the Glass Transition Temperatures by Differential Scanning Calorimetry) [14].

The nanoindentation study was performed on a MFP3D nanoindenter (Asylum Research) equipped with a Berkovich diamond indenter tip at room temperature. The FBE and nanocomposites were deposited on glass supports and the samples were glued on stubs. The coating thickness was approximately $350 \mu \mathrm{m}$ and the contribution of glass substrate to the final results was negligible. The maximum load was $2 \mathrm{mN}$, and the loading and unloading rate was $0.13 \mathrm{mN} \cdot \mathrm{s}^{-1}$. To minimize the viscous creep effect, at the maximum load, the indenter was held for $15 \mathrm{~s}$ before starting unloading. A total of 36 indentations on a $50 \mu \mathrm{m} \times 50 \mu \mathrm{m}$ area were applied on each sample. The curves were analyzed according to the Oliver-Pharr method [15], and the average values of hardness and elastic modulus were reported. Atomic force microscopy (AFM) was performed on the indented areas, after the nanoindentation tests, using an MFP-3D-SA SPM microscope (Asylum Research).

\section{Results and Discussion}

3.1. Characterization of Bare Silica and Amino-Modified Silica Nanoparticles. The sol-gel process is widely used to produce pure silica particles due to the ability of this method to control the particle size, size distribution, and morphology through systematic monitoring of reaction parameters. The process involves hydrolysis and condensation of silicon alkoxides $\left(\mathrm{Si}(\mathrm{OR})_{4}\right)$ such as tetraethylorthosilicate (TEOS, $\left.\mathrm{Si}\left(\mathrm{OC}_{2} \mathrm{H}_{5}\right)_{4}\right)$ in the presence of mineral acid (e.g., $\left.\mathrm{HCl}\right)$ or base (e.g., $\mathrm{NH}_{3}$ ) as catalyst [1]. In this study, the sol-gel process was used to synthesize pure silica and organically modified silica nanoparticles for reinforcement of epoxybased nanocomposite coatings. The TEM results presented in Figure 2 evidenced that the silica nanoparticles were spherical and reasonably monodispersed with the average size of $53 \pm 13 \mathrm{~nm}$, where no significant effect of the amino functionalization was detected on the morphological aspects and size distribution of the silica nanoparticles. In addition, the EDX chemical analysis showed silicon and oxygen as the predominant elements, besides the other constituents of the grid (e.g., copper and carbon). These results demonstrated that nanosized silica particles were successfully produced with dimensions within controllable range via facile sol-gel processing route. It is worth highlighting that the properties of nanomaterials are usually size dependent, which can be designed and produced by controlling the size distribution of the nanoparticles by sol-gel processing route [1]. In addition, the amount of atoms residing on the surface increases with the decrease in particle size, which affects the amount of chemical groups present on the surface, such as silanols $(-\mathrm{Si}-\mathrm{OH})$ and incorporated functional species (i.e., $\left.-\mathrm{NH}_{2}\right)$. Thus, the combination of size and chemical functionalities of silica nanoparticles assigns unique properties to the resulting nanocomposites reinforced by these nanomaterials.

FTIR is used as a powerful tool for accessing the chemical groups during the synthesis after the formation of silica particles and the incorporation of functional groups at the surfaces. In Figure 3 the FTIR spectra of bare silica (a) and amino-modified silica nanoparticles (b) are presented. As a general trend, in both spectra the major chemical species associated with the sol-gel synthesis of silica nanoparticles is clearly observed, such as stretching vibration bands of Si-O$\mathrm{Si}$ at $1130-1000 \mathrm{~cm}^{-1}$ and $800 \mathrm{~cm}^{-1}$. In addition, the stretching vibration bands of $\mathrm{Si}-\mathrm{OH}$ groups at $975-865 \mathrm{~cm}^{-1}$ related to the incomplete condensation of silanols. The broad band at $3700-3200 \mathrm{~cm}^{-1}$ is predominantly assigned to the stretching band of hydroxyl groups $(\mathrm{Si}-\mathrm{OH})$ in the structure and at the surface of the silica nanoparticles. In particular, the FTIR spectrum of Figure 3(b) shows the vibration bands at 3500$3200 \mathrm{~cm}^{-1}$ associated with amine groups $\left(-\mathrm{NH}_{2}\right)$ overlapped with signals from silanol groups and the bands at $1573 \mathrm{~cm}^{-1}$ and $1318 \mathrm{~cm}^{-1}$ that are associated with the in-plane scissoring bending of primary amines $\left(-\mathrm{NH}_{2}\right)$ and the stretching of -CN bonds, respectively [16]. Moreover, alkyl bands $\left(-\mathrm{CH}_{2}\right)$ were detected at $2925,2853 \mathrm{~cm}^{-1}$, and $1465 \mathrm{~cm}^{-1}$, which were assigned to the stretching and bending contributions of propyl groups present in the organosilane used as chemical surface modifier. Hence, these results evidenced that silica nanoparticles were produced by the sol-gel process with silanol groups incorporated in the structure. Furthermore, it was possible to chemically modify the system by adding 


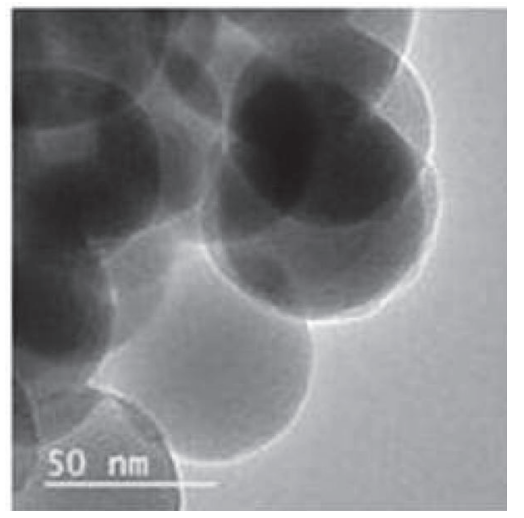

(a)

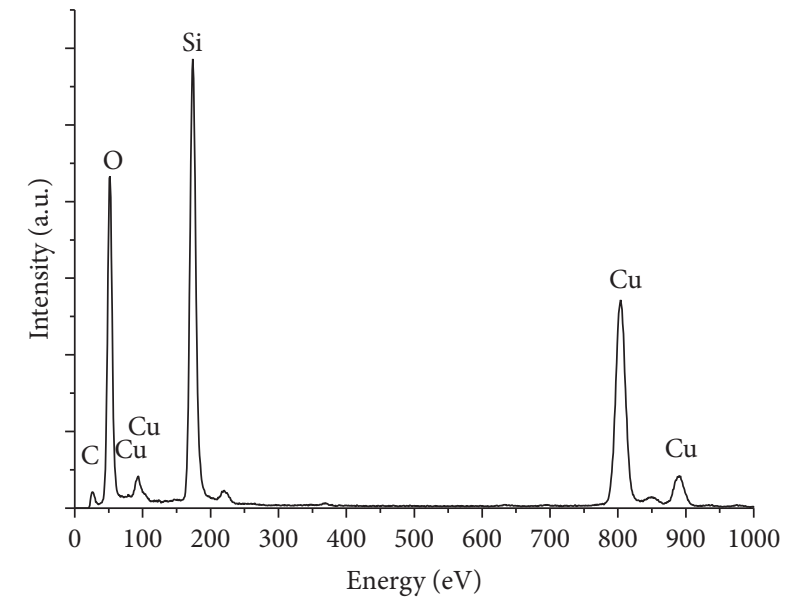

(b)

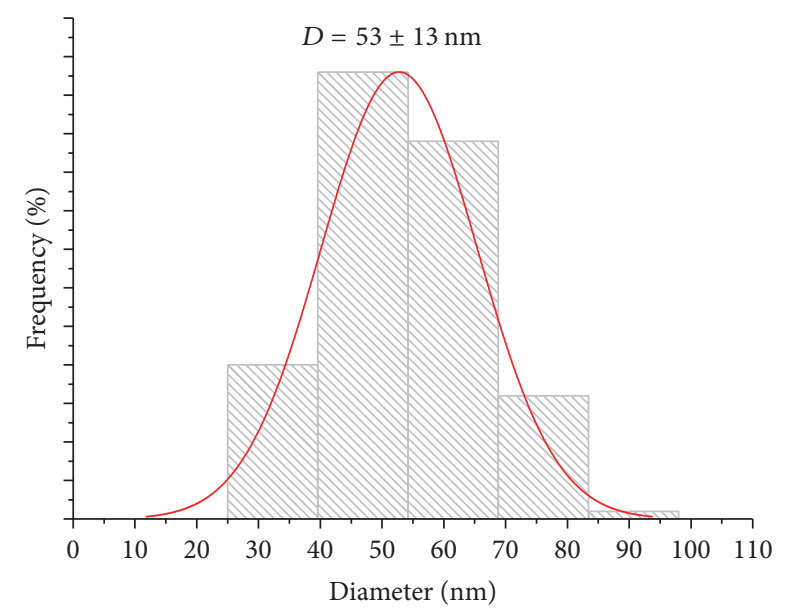

(c)

FIgURE 2: (a) Typical TEM image of silica nanoparticles. (b) EDX spectrum of silica nanoparticles. (c) Nanoparticles size distribution.

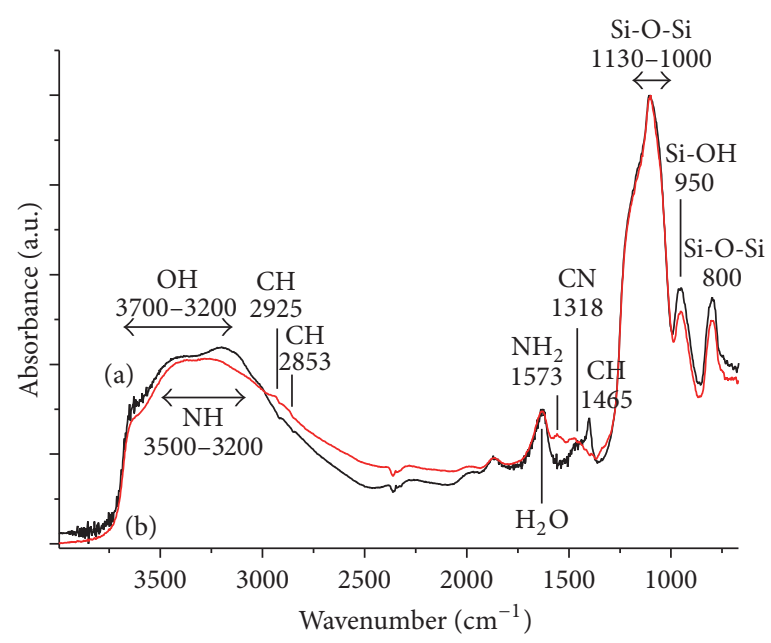

FIGURE 3: FTIR spectra of (a) silica nanoparticles and (b) silica nanoparticles modified by 3-APTES. 


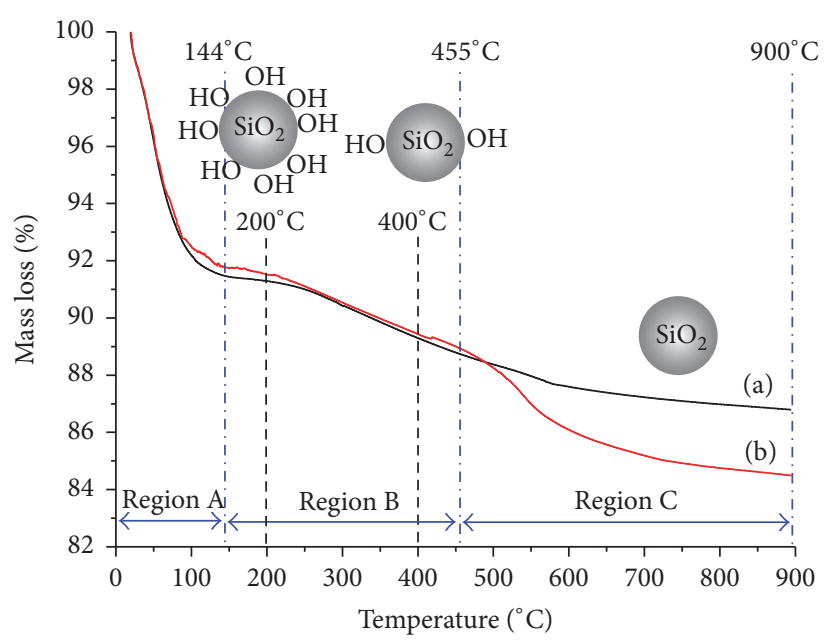

FIGURE 4: Thermal analyses of silica nanoparticles (a) before and (b) after surface functionalization with 3-APTES.

amino-derived organosilane precursor during the sol-gel synthesis, leading to the formation of surface-functionalized silica nanoparticles. These aspects are relevant as far as the reinforcement of composite with nanoparticle is concerned because they offer chemical functional groups for the reaction with the epoxy-based matrix, which can potentially change the overall properties of the system.

Thermogravimetric (TG) analyses of the silica nanoparticles are presented in Figure 4. TG analyses showed twostage mass losses for bare silica nanoparticles (regions A and B) and three stages for amino-functionalized silica samples (3-APTES, regions A, B, and C) as shown in Figures 4(a) and 4(b), respectively. Essentially, for both silica samples (a and b) significant mass losses of approximately $8 \%$ below the temperature of $144^{\circ} \mathrm{C}$ (region A, Figure 4) can be observed, which were assigned to the drying process by evaporation and desorption of liquids, that is, ethanol and water molecules, from the silica nanoparticulate system [17]. The second stage of mass loss at region B of approximately $2 \%$, between $144^{\circ} \mathrm{C}$ and $455^{\circ} \mathrm{C}$ (Figure 4), was predominantly associated with the release of trapped water within the pore, degradation of residual unreacted precursors (e.g., alcohol, ammonia, and silane), and dehydroxylation of silanol groups ( $\mathrm{Si}-\mathrm{OH})$ and formation of siloxane linkage ( $\mathrm{Si}-\mathrm{O}-\mathrm{Si}$ ) [18]. Finally, from $455^{\circ} \mathrm{C}$ to $900^{\circ} \mathrm{C}$ (region $\mathrm{C}$ ) silica nanoparticles presented just minor gradual mass loss $(\sim 1 \%)$ mostly due to the further increase in siloxane bonds and reduced surface hydroxyl groups. However, the amino-modified nanoparticles showed significant additional mass loss of approximately $4 \%$, as a result of the degradation of the aminopropyl functional groups at the surface of the silica nanoparticles. The identification of these stages is very important because they evidenced the transition temperatures and range of temperature required for posterior thermal treatment of the silica nanoparticles after the synthesis in order to promote their densification and thermochemical stabilization. This aspect is crucial for utilizing these silica nanoparticles as inorganic reinforcements of epoxy-based nanocomposites. Therefore, based on the aforementioned reasons, this study used the heat thermal treatment of the silica nanoparticles (bare and amino-modified) at temperatures $200^{\circ} \mathrm{C}$ and $400^{\circ} \mathrm{C}$ in order to promote their thermochemical stabilization prior to the incorporation in the epoxy matrix. The curing temperature of the epoxy matrix was $248^{\circ} \mathrm{C}$, much lower than the temperature of the thermally stabilized silica nanoparticles avoiding any degradation, which would negatively affect the properties of the FBE nanocomposite coatings.

The freshly synthesized silica nanoparticles (in gel form) were dried under heat drying in oven for $2 \mathrm{~h}$. Drying process can cause the decrease in gel volume due to the loss of liquid by evaporation through the silica pore. Conversely, silica nanoparticles tend to coalesce upon heating, which can lead to changes in the average size of the nanoparticles. In this study, particle size distribution of the two silica nanoparticulate systems, with and without surface chemical functionalization, showed no significant statistical difference before and after the thermal treatment at $200^{\circ} \mathrm{C}$ and $400^{\circ} \mathrm{C}$. SEM images (Figure 5) reveal a relative narrow size distribution and sphere-like shape on the morphological aspects of the nanosize particles with roughly intermediate aggregation and agglomeration "as synthesized" (Figures 5(a) and 5(b)) due to presence of interparticle moisture. After heating at the temperatures of $200^{\circ} \mathrm{C}$ (Figures 5(c) and 5(d)) and $400^{\circ} \mathrm{C}$ (Figure $5(\mathrm{e})$ ) a relative gradual reduction of agglomerates was observed, leading to more uniformly dispersed nanoparticulate systems mostly caused by the removal of water molecules upon heating and, therefore, decreasing the attractive hydrogen bonds between silica nanoparticles [19].

The broad range of applications of silica nanoparticles is often determined by the particle size in the colloidal media. Dynamic light scattering (DLS) is a characterization technique that provides fast, accurate, and repeatable nanoparticle size data and therefore is an essential tool for the preliminary investigation of silica nanoparticles produced via 


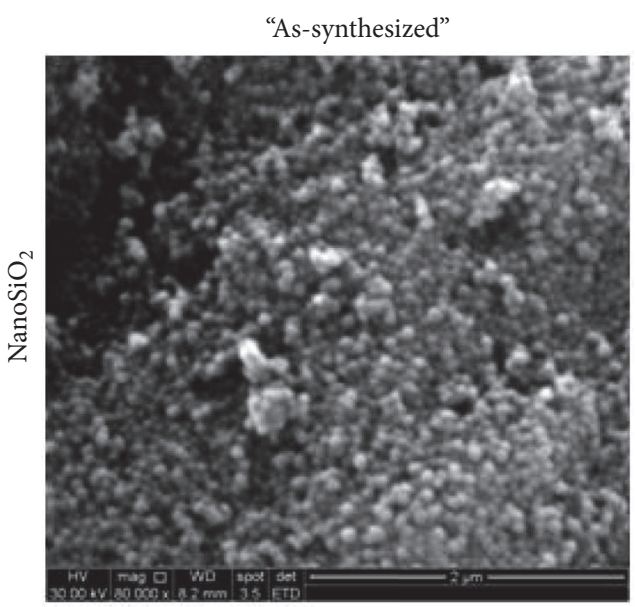

(a)

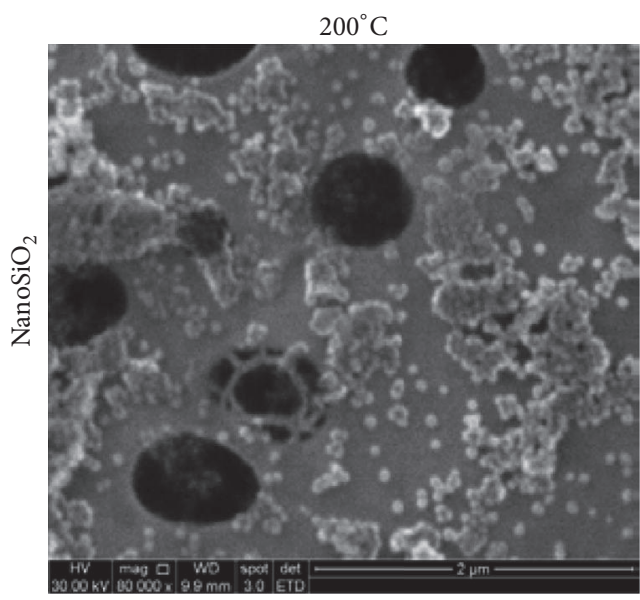

(c)

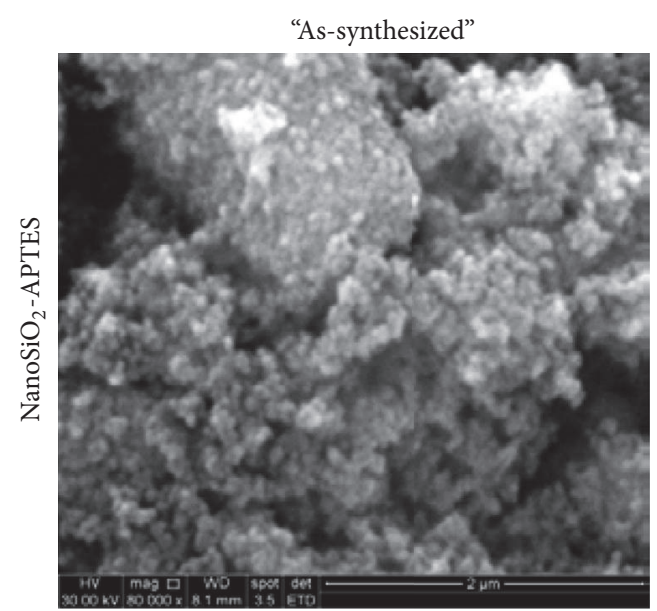

(b)

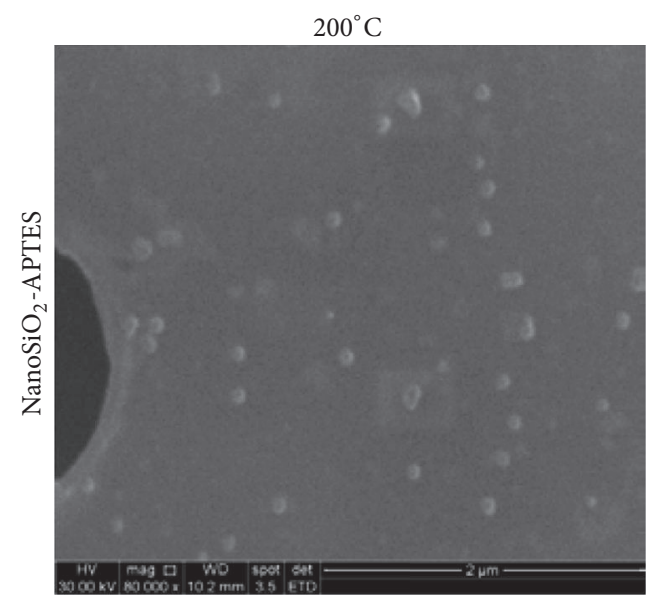

(d)

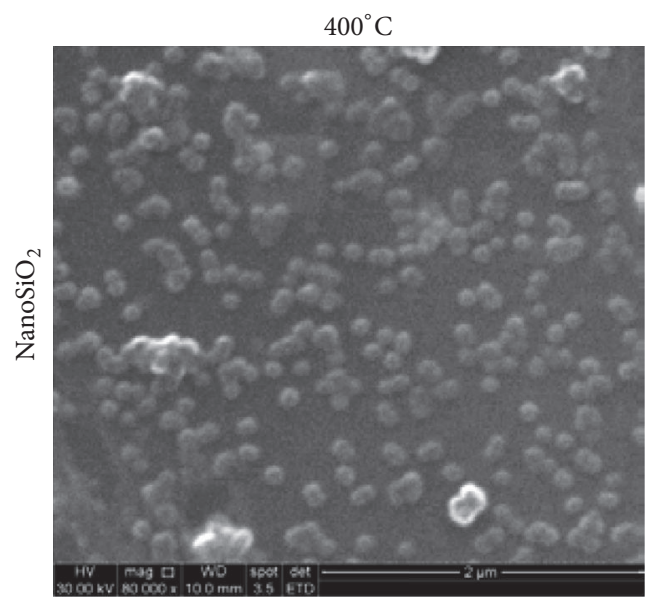

(e)

FIGURE 5: SEM images of silica nanoparticles "as synthesized" ((a) nonfunctionalized and (b) amino-functionalized) and after heating at $200^{\circ} \mathrm{C} \mathrm{((c)} \mathrm{nonfunctionalized} \mathrm{and} \mathrm{(d)} \mathrm{amino-functionalized)} \mathrm{and} \mathrm{at} 400^{\circ} \mathrm{C}((\mathrm{e})$ nonfunctionalized).

sol-gel chemistry and the effect of surface functionalization by organic species. Hence, in this study, DLS measurements were performed in order to evaluate the hydrodynamic radius $\left(H_{D}\right)$ of the silica nanoparticles as synthesized and after surface functionalization with aminopropyl silane. The results are presented in Figure 6, with average $H_{D}$ values of $93 \pm 9 \mathrm{~nm}$ and $152 \pm 65 \mathrm{~nm}$ (polydispersity index $=$ 0.032 ) for bare silica nanoparticles (Figure 6(a)) and 

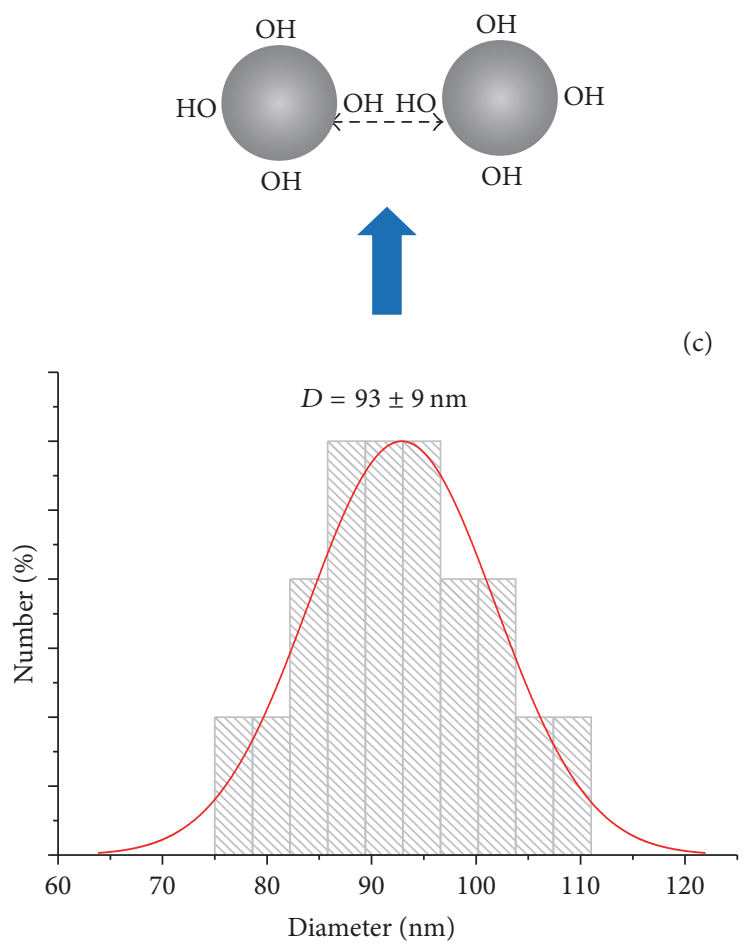

(a)

(c)
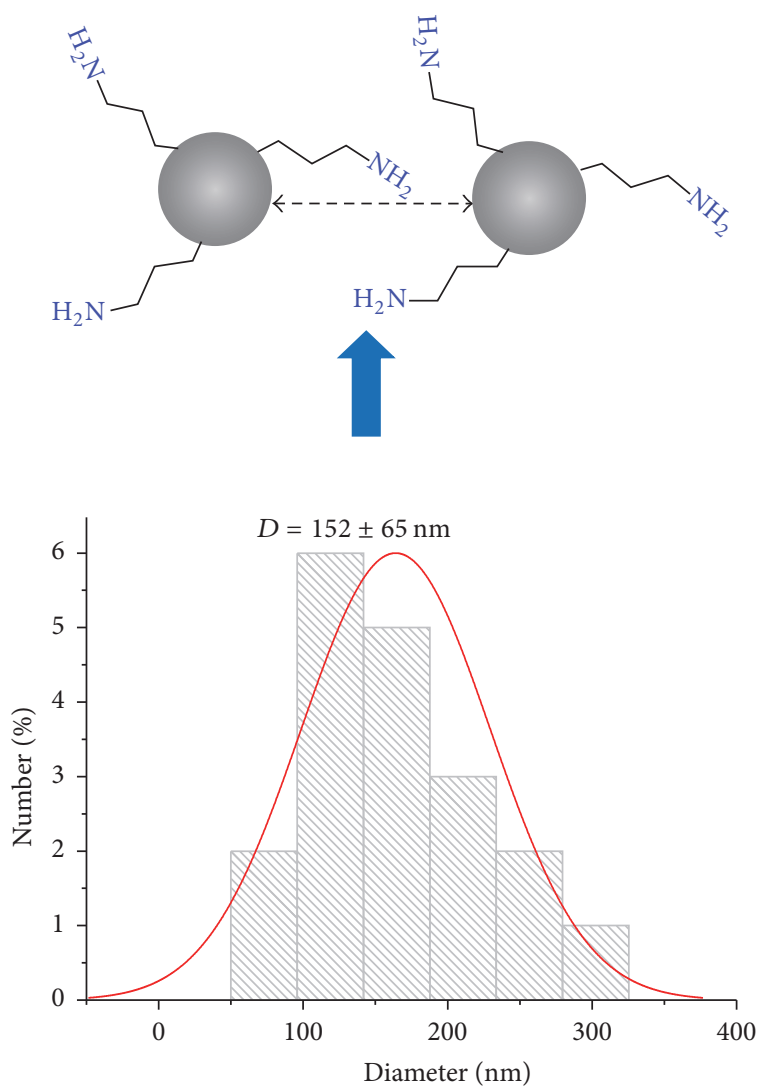

(b)

FIGURE 6: DLS measurements of silica nanoparticles (a) before and (b) after surface functionalization with 3-APTES. (c) Schematic representation of surface interaction of silica nanoparticles in water medium.

APTES-silica nanoparticles (Figure 6(b)), respectively. These size distribution plots indicated the formation of reasonably monodispersed systems [20]. In addition, the results demonstrated the effective chemical functionalization of the silica nanoparticle surfaces, which caused the drastic increase in $H_{D}$ of the silica-modified nanoparticles (i.e., interparticle spacing), because of the steric hindrance and repulsion of hydrophobic aminopropyl groups at the surfaces dispersed in the hydrophilic water medium. The suggested schematic representation of the silica nanoparticles colloidal systems synthesized in this work is depicted in Figure 7.

\subsection{Characterization of Epoxy-Based Nanocomposite Coating} Reinforced with Silica and Surface-Modified Nanoparticles. Epoxy resin of Scotchkote $226 \mathrm{~N}$ is based on poly(bisphenol A-co-epichlorohydrin) end-capped glycidyl (DGEBA, Figure $8(\mathrm{a})$ ) and dicyandiamide (DDA, Figure $8(\mathrm{~b})$ ) as the curing agent. Despite the complex mechanisms and reactions involved the curing process starts with the diffusion of the dicyandiamide into the epoxy resin and the reaction between the oxirane rings of DGEBA and primary and secondary amine groups of the dicyandiamide breaking the oxirane ring and forming hydroxyl groups. As the reaction proceeds, the formed hydroxyl groups can react with cyano and oxirane groups leading to the formation of a highly crosslinked network [21-23].

SEM images obtained from freeze-fractured surfaces of coatings are shown in Figure 9. BSE image of FBE coating (Figure 9(a)) indicated that it is a composite material with inorganic particles (bright) immersed in the polymeric matrix (dark). As reported in a previous study developed by our group [9], the inorganic filler of FBE used in this study consists of small rounded anatase $\left(\mathrm{TiO}_{2}\right)$ particles and needle-shaped wollastonite $\left(\mathrm{CaSiO}_{3}\right)$ with different grades of aspect ratio in an amount of $32.8 \pm 3.0 \mathrm{wt}$.\%. Morphologies of FBE nanocomposites reinforced with $\mathrm{NanoSiO}_{2}$ (Figure 9(b)) and $\mathrm{NanoSiO}_{2}$-APTES (Figure 9(c)) were similar to those observed for original FBE with only small agglomerates of silica nanoparticles (red arrows), with dimensions smaller than the calcium silicate nanoparticles. For all coating samples, secondary electron images of fractured materials (Figures 9(d), 9(e), and 9(f)) revealed a surface with distracted patterns that is characteristic of epoxy matrix reinforced with particles. This feature is usually associated with the presence of well bonded filler materials causing local yielding of the epoxy matrix, in contrast to the smooth and glassy brittle fracture surface of pure epoxy reported in literature [24]. In this sense, the addition of 


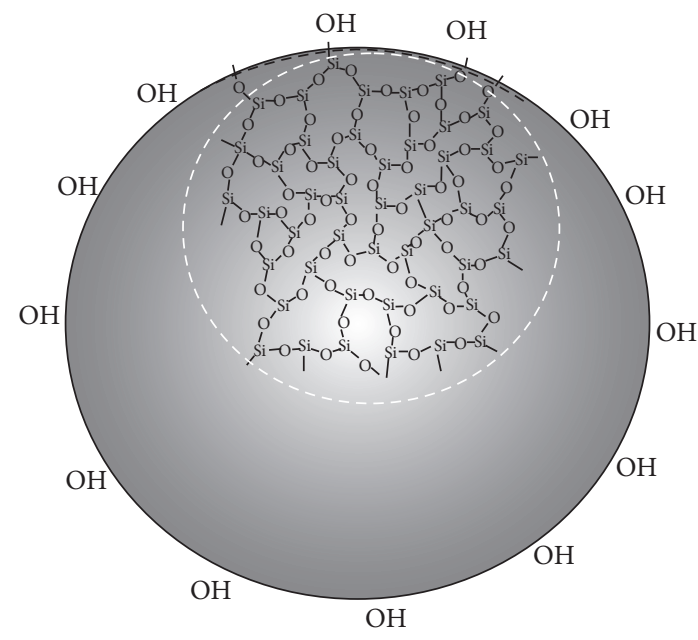

(a)

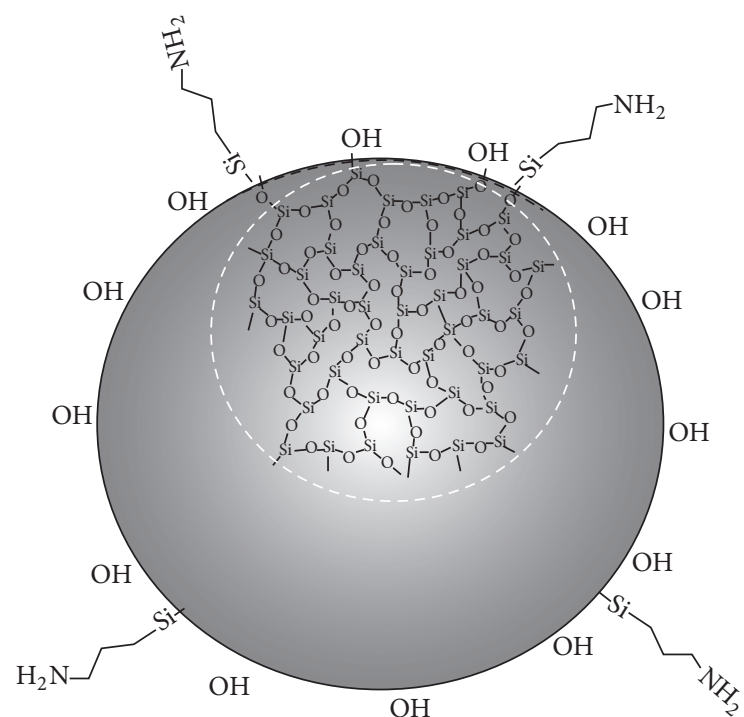

(b)

FIGURE 7: Schematic representation of nanoparticle chemical structure: (a) $\mathrm{NanoSiO}_{2}$ and (b) $\mathrm{NanoSiO}_{2}-\mathrm{APTES}$.<smiles>CC(C)(c1ccccc1)c1ccc(OCC(O)COc2cccc(C(C)(C)c3cccc(OCC4CO4)c3)c2)cc1</smiles>

(a)<smiles>N#CN=C(N)N</smiles>

(b)

FIgURE 8: Chemical structures of DGEBA (a) and DDA (b).

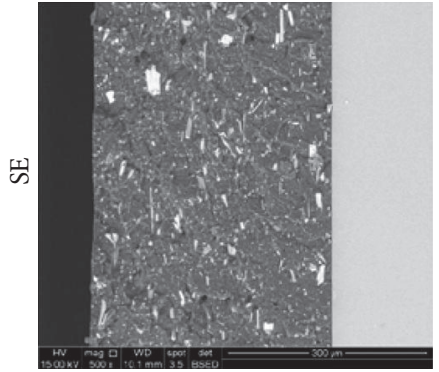

(a)

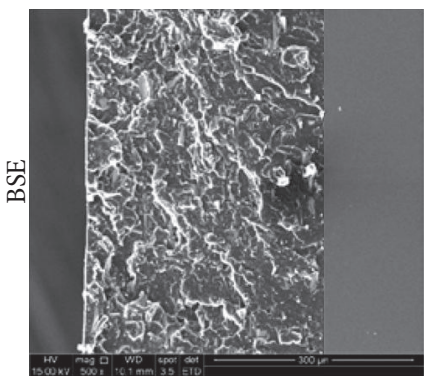

(d)

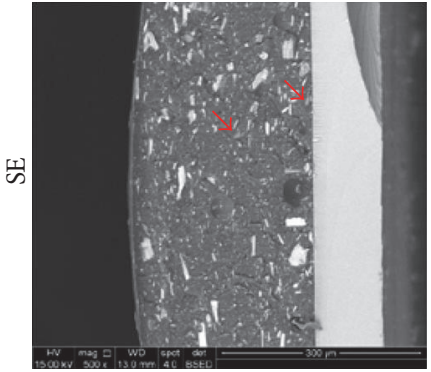

(b)

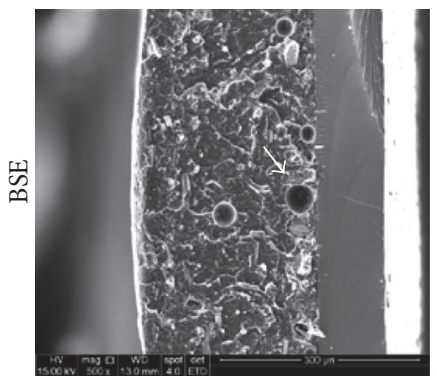

(e)

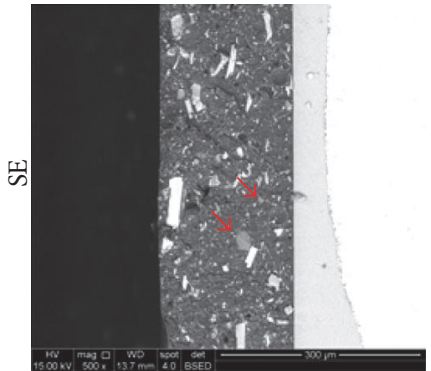

(c)

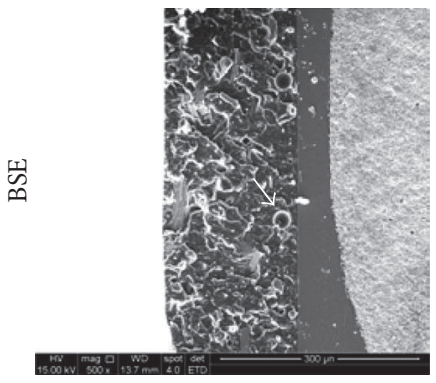

(f)

Figure 9: Morphological analysis of FBE coatings (a and d) FBE, (b and e) FBE-NanoSiO ${ }_{2}$, and (c and f) FBE-NanoSiO ${ }_{2}$-APTES (red arrows, $\mathrm{SiO}_{2}$ agglomerates, and white arrows, voids). 


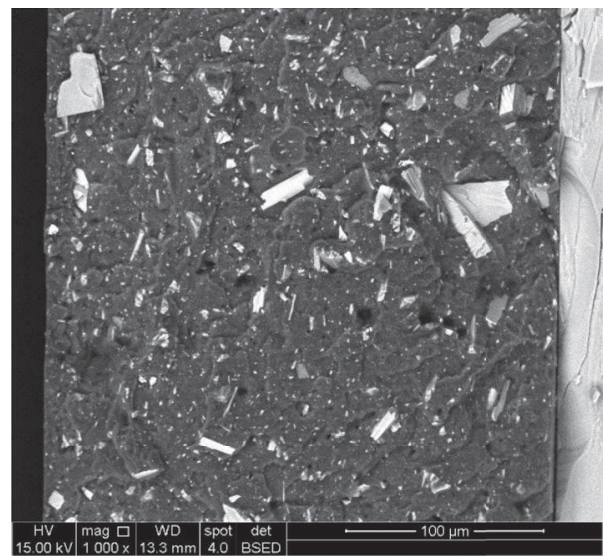

FIGURE 10: Typical SE image of FBE-NanoSiO ${ }_{2}$-APTES coating with nanoparticles heat dried at $400^{\circ} \mathrm{C}$.

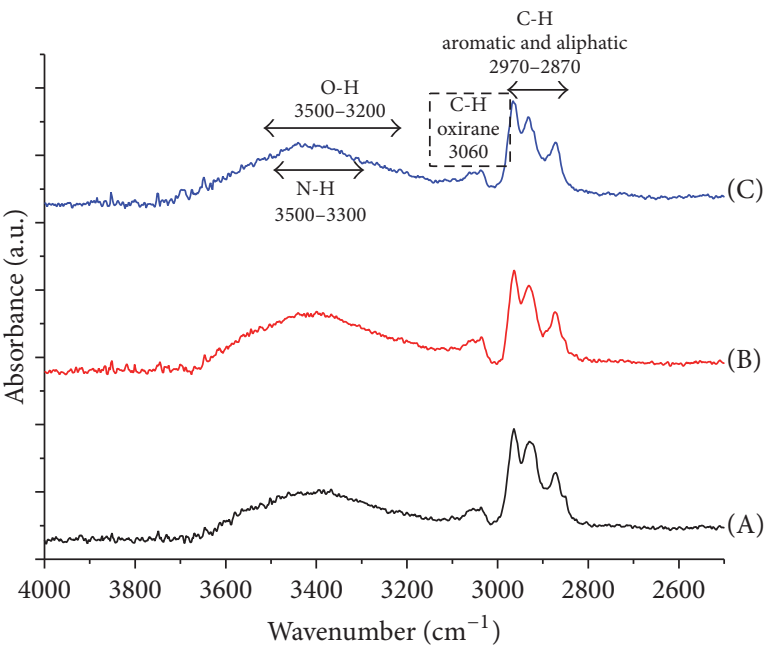

(a)

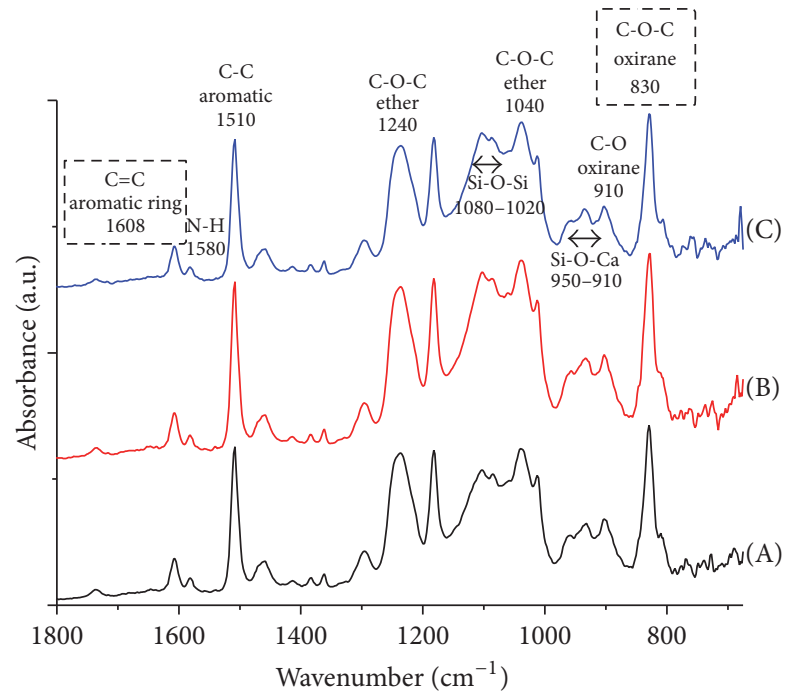

(b)

FIGURE 11: FTIR spectra of (A) FBE, (B) FBE-NanoSiO ${ }_{2}$, and (C) FBE-NanoSiO - APTES in the spectral range of $4000-2500 \mathrm{~cm}^{-1}$ (a) and $1800-675 \mathrm{~cm}^{-1}(\mathrm{~b})$.

nanofiller into the FBE composite did not significantly affect the fracture surface, probably due to the small amount of $\mathrm{SiO}_{2}$ nanoparticles (1.0 wt.\%) incorporated in epoxy-based material that already presented microsized inorganic fillers. The main difference between the FBE composite and the FBE nanocomposites (FBE-NanoSiO ${ }_{2}$ and $\mathrm{FBE}-\mathrm{NanoSiO}_{2}-$ APTES) is the presence of some voids in the epoxy matrix due to the presence of residual volatile components (Figures 9(e) and 9 (f), white arrows) $[18,25]$. Based on the thermal analysis of the silica nanoparticles presented in Section 3.1, there is still a loss of mass associated with the condensation of silanol groups, release of trapped water, and degradation of residual unreacted precursors at curing temperature $\left(248 \pm 5^{\circ} \mathrm{C}\right)$ that is higher than the temperatures of $200^{\circ} \mathrm{C}$ used to stabilize and disperse the nanoparticles. On the other hand, no voids were observed for silica nanoparticles thermally treated at $400^{\circ} \mathrm{C}$ (Figure 10).
Based on precursors and main reactions involved in the formation of crosslinked epoxy matrix, midinfrared spectrum of cured FBE presented vibration bands associated with hydroxyl groups, oxirane ring, methyl and methylene groups, and $\mathrm{C}=\mathrm{C}$ and $\mathrm{C}-\mathrm{C}$ bonds in aromatic structures, besides ether and primary and secondary amines as depicted in Figure 11 [21, 22, 26, 27]. In addition, bands associated with the silicate mineral filler ( $\mathrm{Si}-\mathrm{O}-\mathrm{Si}$ and $\mathrm{Si}-\mathrm{O}-\mathrm{Ca}$ ) were also observed.

To perform a deeper analysis, the curing extent of each system (FBE, FBE-NanoSiO ${ }_{2}$, and FBE-NanoSiO 2 -APTES) was evaluated by the absorbance intensity (A) of two bands related to oxirane ring $\left(830 \mathrm{~cm}^{-1}\right.$ and $\left.3060 \mathrm{~cm}^{-1}\right)$ normalized using the absorbance intensity of the $\mathrm{C}=\mathrm{C}$ band of phenyl ring at $1608 \mathrm{~cm}^{-1}$ that is not involved in curing reactions remaining constant throughout [28]. The oxirane ring bands decrease upon curing as a consequence of the 


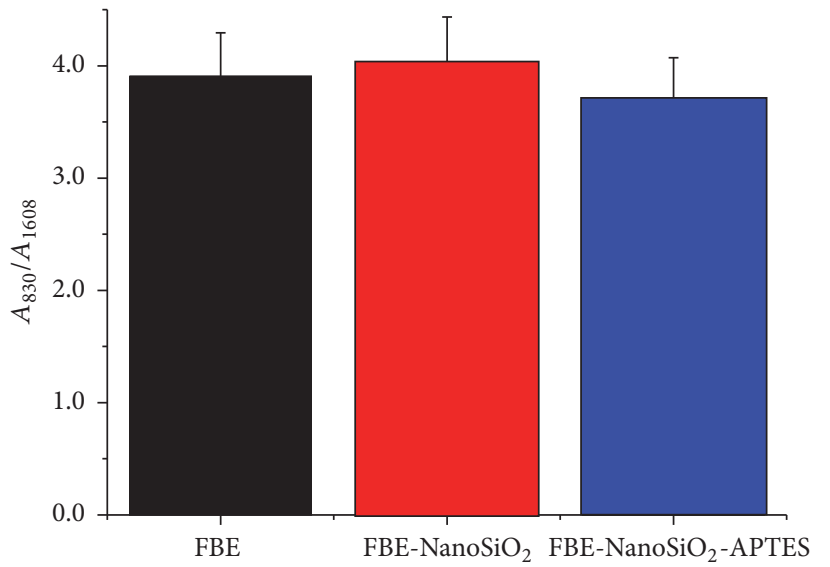

(a)

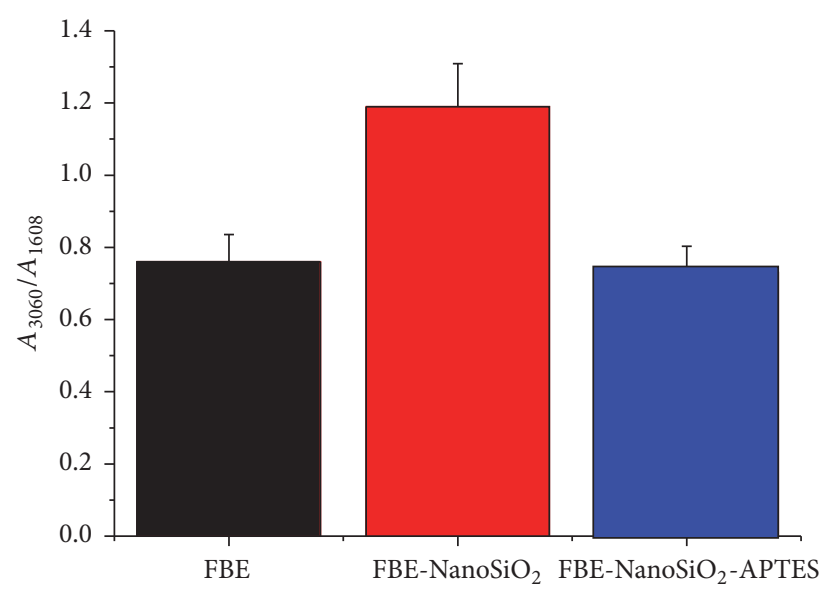

(b)

FIGURE 12: Relative intensity of oxirane bands at (a) $830 \mathrm{~cm}^{-1}$ and (b) $3060 \mathrm{~cm}^{-1}$ of the FBE coatings.

epoxy ring opening and, as the relative intensity of FTIR band is proportional to the relative concentration of the components in a sample, the results of the ratio of $A_{830} / A_{1608}$ and $A_{3060} / A_{1608}$ (Figures $12(\mathrm{a})$ and $12(\mathrm{~b})$, resp.) revealed that the FBE-NanoSiO ${ }_{2}$-APTES presented a higher degree of consumption of epoxy resin followed by FBE and FBE$\mathrm{NanoSiO}_{2}$. FTIR image maps (FTIR-I analysis) of oxirane band at $830 \mathrm{~cm}^{-1}$ showed oxirane distribution in the sample (Figure 13). As blue and red colors indicate low and high oxirane content, respectively, the same trend was observed: an increase of nonreacted epoxy groups in the nanocomposite with unmodified silica nanoparticles. This may be explained based on matrix-nanoparticle interactions, where the incorporation of nanoparticles with high surface area in epoxy composite leads to intermolecular interactions between nanoparticles and polymer chains during curing process. As $\mathrm{NanoSiO}_{2}$-APTES nanoparticles present amine groups at the surfaces, covalent bonds between organofunctional group from surface modifier and epoxy groups from FBE can occur promoting the opening of oxirane rings. On the contrary, the epoxy- $\mathrm{NanoSiO}_{2}$ interaction may prevent the contact of dicyandiamide curing agent with the epoxy resin.

In addition to FTIR analysis, the changes in glass transition temperature $\left(T_{g}\right)$ of the cured epoxy coating (referred to as $T_{g_{2}}$ ) can be used to characterize the degree of cure of the epoxy resin. In Figure 14, the results of $T_{g_{2}}$ of coatings after the curing treatment obtained from DSC curves are displayed, where FBE-NanoSiO $\mathrm{S}_{2}$-APTES nanocomposite presented higher $T_{g_{2}}$ than FBE. As the epoxy curing process evolves, the degree of crosslinking increases, and the chains motion becomes more restricted. As a consequence, the glass transition temperature shifts to higher values, which can be readily observed by DSC analysis. These results are in agreement with FTIR analysis indicating that, besides the crosslinking promoted by reaction between DGEBA and DDA, the epoxy resin may have also reacted with the
TABLE 2: Elastic modulus $(E)$, hardness $(H)$, and the ratio $(E / H)$ of the samples tested.

\begin{tabular}{lccc}
\hline Sample & $E(\mathrm{GPa})$ & $H(\mathrm{MPa})$ & $E / H$ \\
\hline FBE & $3.6 \pm 1.0$ & $282 \pm 81$ & $12.8 \pm 0.6$ \\
FBE-NanoSiO $_{2}$ & $3.5 \pm 0.4$ & $273 \pm 47$ & $12.7 \pm 0.3$ \\
FBE-NanoSiO $_{2}$-APTES & $4.2 \pm 1.0$ & $331 \pm 103$ & $12.7 \pm 0.6$ \\
\hline
\end{tabular}

amino-modified nanofiller. The opposite effect was observed for $\mathrm{FBE}-\mathrm{NanoSiO}_{2}$ revealing incomplete crosslinking in the presence of $\mathrm{NanoSiO}_{2}$ particles.

Figure 15(a) shows the load displacement curves for the nanoindentation tests and Figure 15(b) the AFM image of a representative nanoindentation mark. Figures 15(c), 15(d), and 15(e) show the variation of the main parameters obtained by nanoindentation tests summarized in Table 2 . The ratio between the elastic modulus $(E)$ and the hardness $(H)$ can be correlated with the fracture toughness of the coatings, if the geometry and the dimension of the nanoindentation marks are very similar [29-31]. The elastic modulus and hardness parameters measured for the original FBE are comparable to the reported values of epoxy coatings [32]. However, it can be observed that the addition of silica nanoparticles chemically modified by 3-APTES in FBE (FBE-NanoSiO ${ }_{2}^{-}$ APTES) significantly increased the elastic modulus and the hardness of coating by approximately $17 \%$. Thus, these nanomaterials behaved as reinforcements in the epoxy-based matrix of FBE mostly due to the combination of two aspects: (a) the high superficial interfacial area between the epoxy resin and these nanoparticles and (b) the chemical reaction of epoxy oxirane groups with the amine-modified surfaces of the nanoparticles $[33,34]$. The second aspect predominantly accounted for the higher effect as the nanosilica particles without chemical modification did not present detectable changes in these parameters compared to the original FBE system. Finally, the ratio $E / H$, which can be correlated 


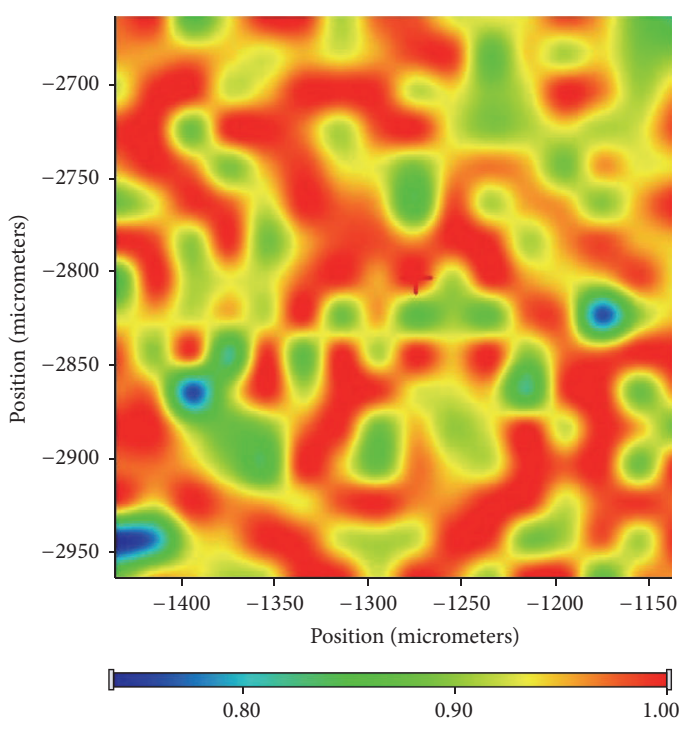

(a)

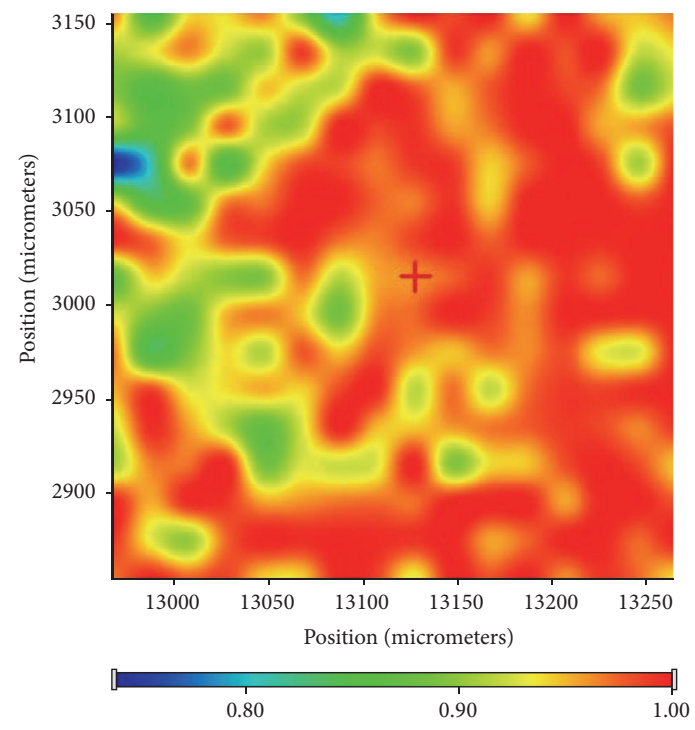

(b)

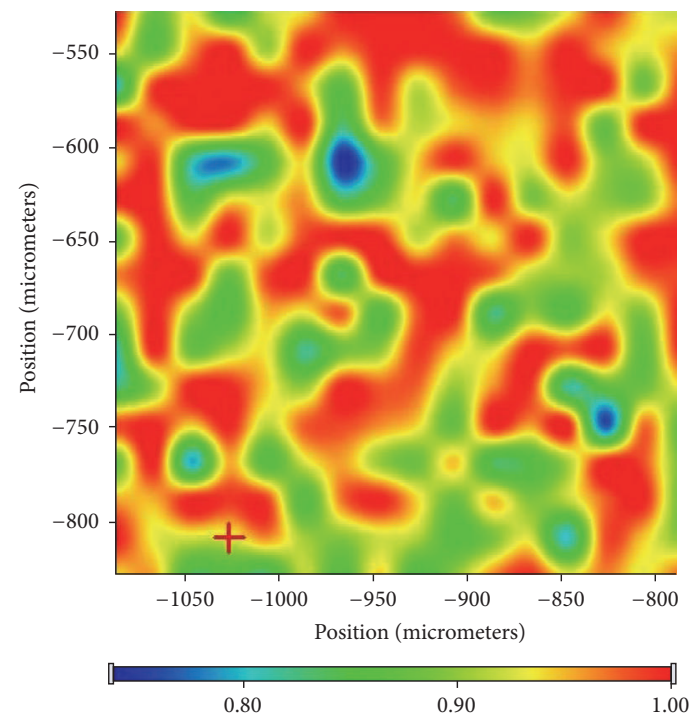

(c)

FIGURE 13: FTIR-I image mapping of oxirane band at $830 \mathrm{~cm}^{-1}$ for (a) FBE, (b) FBE-NanoSiO ${ }_{2}$, and (c) FBE-NanoSiO 2 -APTES.

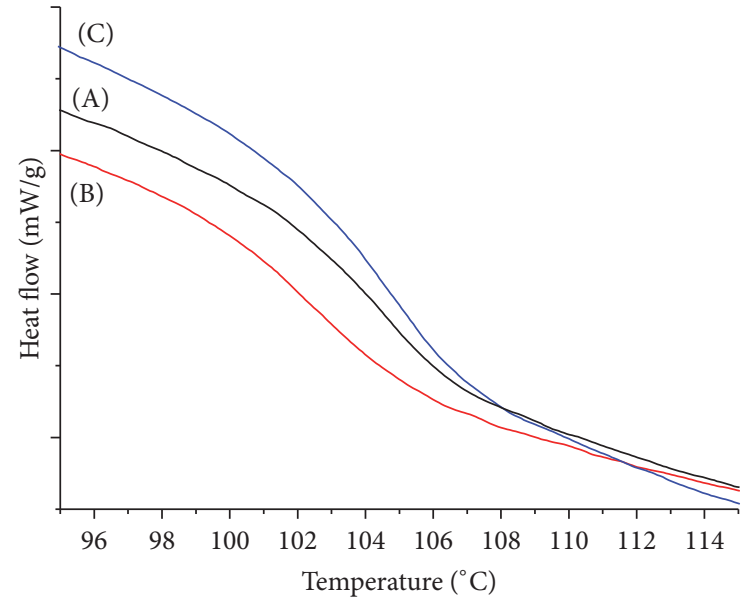

(a)

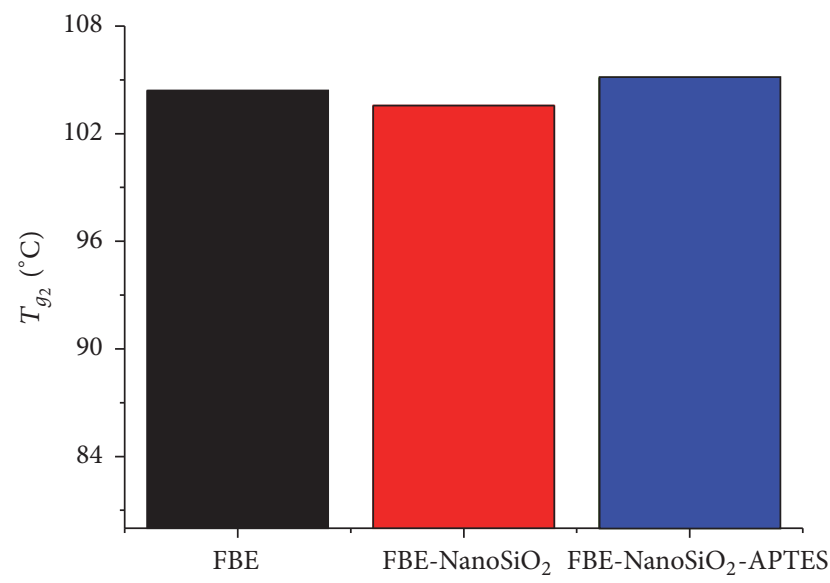

(b)

FIgure 14: (a) DSC curves for (A) FBE, (B) FBE-NanoSiO ${ }_{2}$, and (C) FBE-NanoSiO ${ }_{2}$-APTES. (b) Histogram of $T_{g_{2}}$ values of the composite samples. 


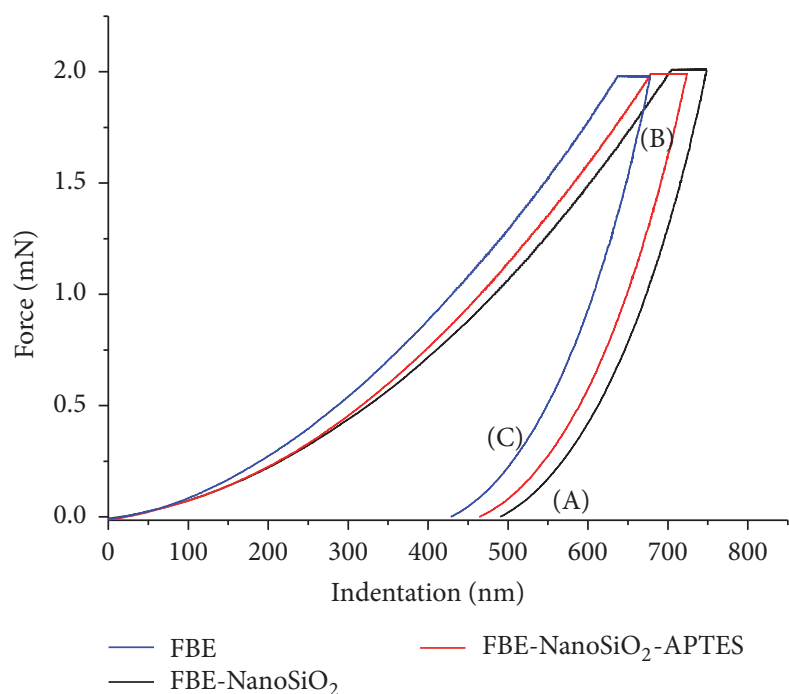

(a)

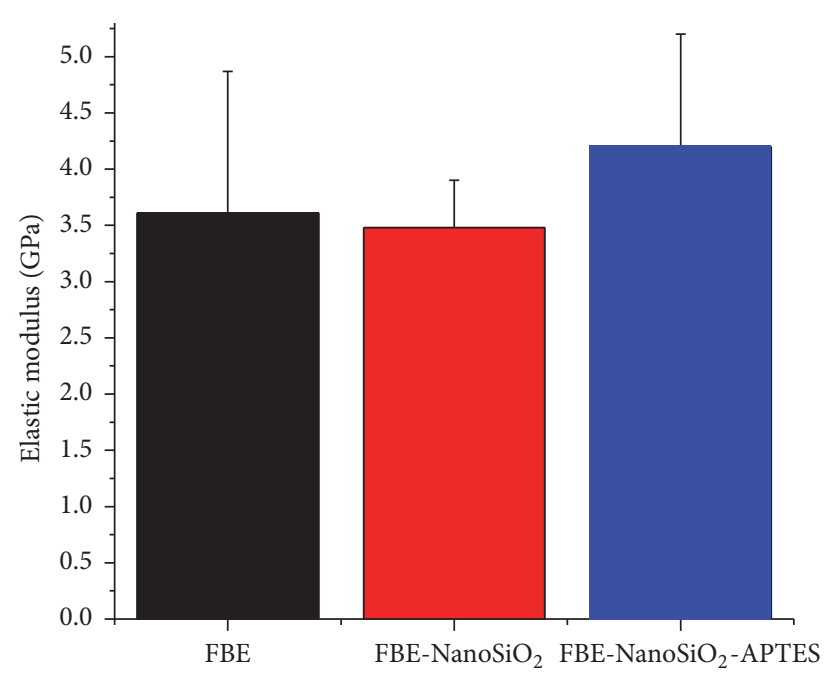

(c)

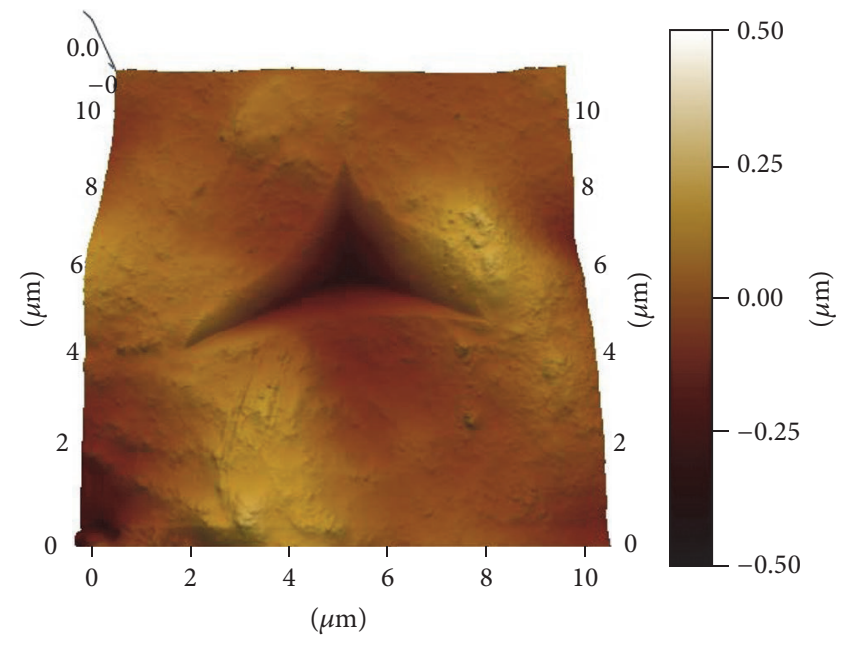

(b)

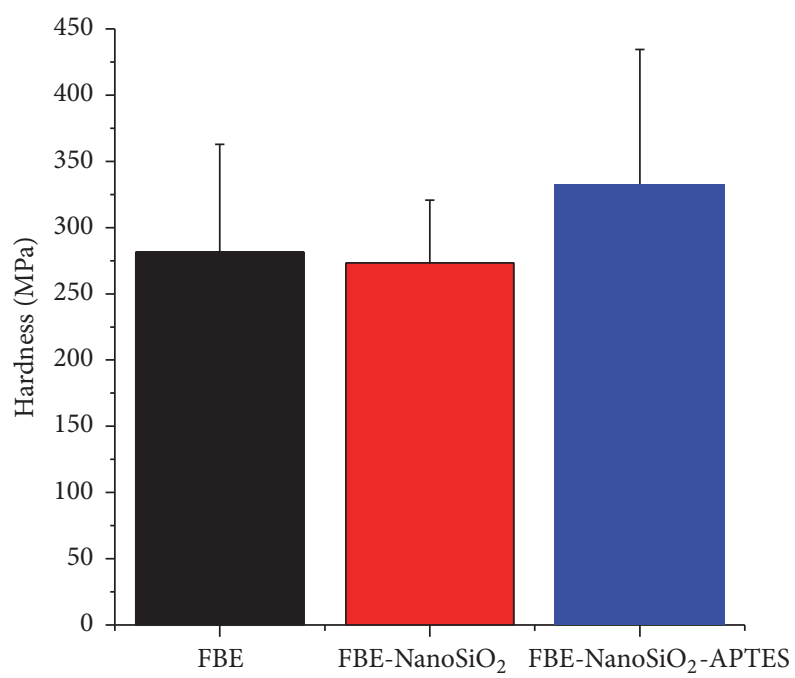

(d)

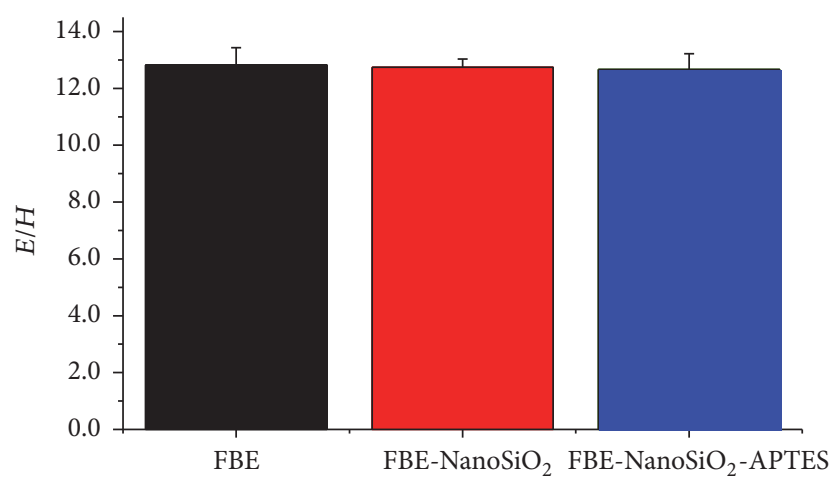

(e)

Figure 15: (a) Force-displacement curves of nanoindentation of FBE (A), FBE-NanoSiO 2 (B), and FBE-NanoSiO ${ }_{2}-\mathrm{APTES}$ (C). (b) AFM image showing the nanoindentation mark produced. (c) Elastic modulus, (d) hardness, and (e) the ratio $E / H$ for the three nanoindentation tests. 


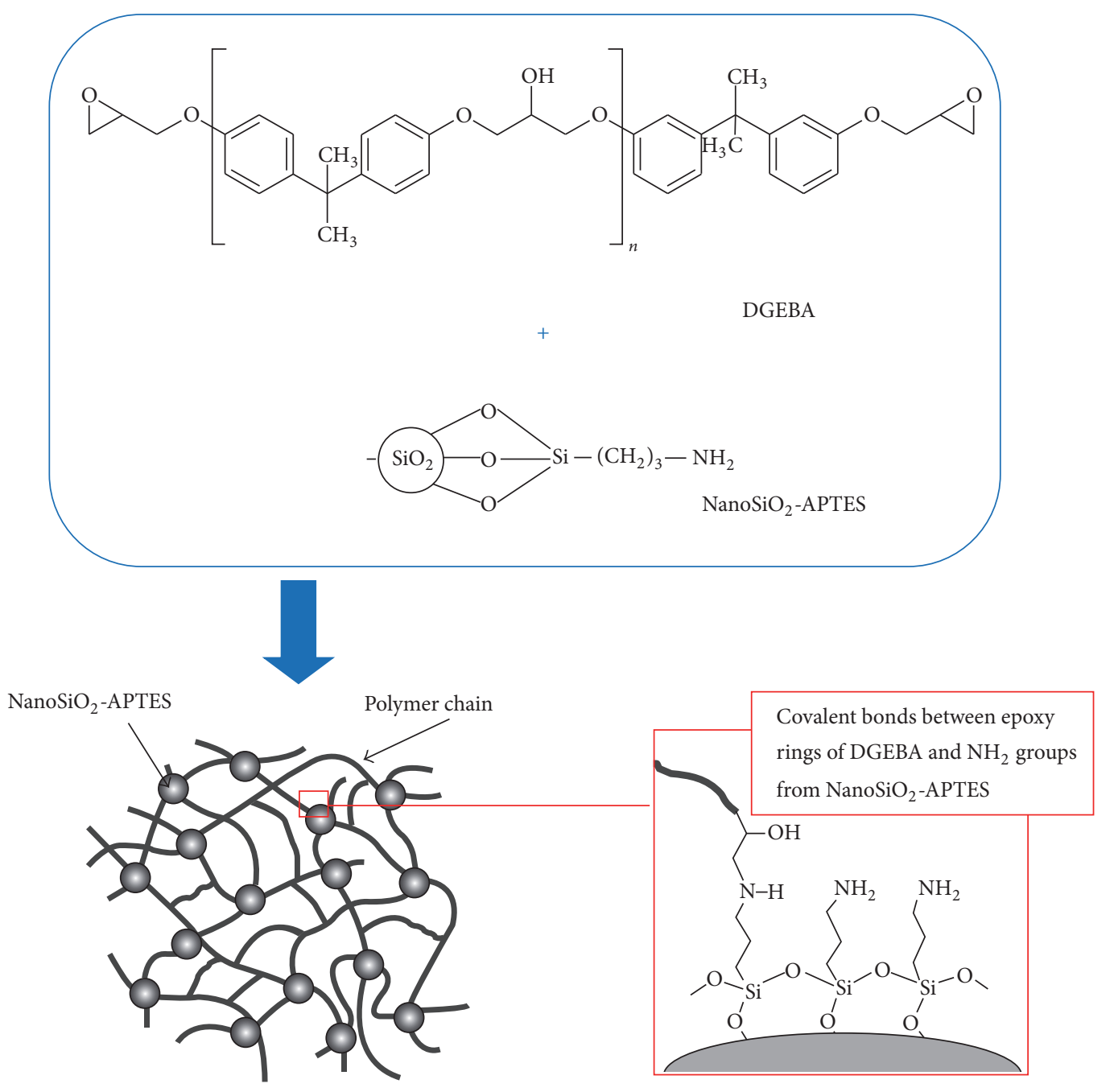

FIGURE 16: Schematic representation at the interface polymer-nanofiller in $\mathrm{FBE}-\mathrm{NanoSiO}_{2}-\mathrm{APTES}$ nanocomposite.

with fracture toughness of the coatings, has not changed significantly among the samples. Therefore, the mechanical properties were increased by the incorporation of aminomodified silica nanoparticles in the FBE without affecting the toughness of nanocomposite, which is relevant as far as the application in high-performance coatings is concerned.

Figure 16 shows schematic drawings of the interactions between $\mathrm{NanoSiO}_{2}$-APTES and FBE that can enhance mechanical properties through the development of covalent bonds between the organofunctional group from surface modifier and the cured FBE.

\section{Conclusion}

In this work, nanosized silica particles were successfully produced using sol-gel process with organosilane precursors, characterized by the formation of monodisperse size distributions (53 $\pm 13 \mathrm{~nm}$ ) of bare silica and aminopropylmodified silica nanoparticles $\left(\mathrm{NanoSiO}_{2}\right.$ and $\mathrm{NanoSiO}_{2}$ APTES). The SEM and TEM analyses showed that these silica nanoparticles were uniformly dispersed in the FBE epoxy powder and, after the thermal treatment and curing process, led to the formation of homogenous nanocomposite coatings (nanoFBE). Midinfrared spectroscopy (MID) combined FTIR microscopy demonstrated that the amino-modified silica nanoparticles ( $\mathrm{NanoSiO}_{2}$-APTES) reacted with the bisphenol-A diglycidyl ether from the FBE epoxy matrix, causing the formation of interfacial covalent bonds, which render more uniform nanocomposite coatings and increased the glass transition temperature compared to the FBE coating without nanoparticle reinforcement. These results were interpreted as the combination of several chemical reactions that may have occurred with the different chemical functional groups present in the system, besides the amino groups, such 
as silanol groups at the surface of the silica nanoparticles with the epoxy ring and with the dispersed inorganic components (calcium silicates and $\mathrm{TiO}_{2}$ particles) already present in the composition of FBE composite powder. These interfacial reactions between organic-inorganic and inorganicinorganic components produced hybrid nanostructures in the novel composite matrix, which have improved the mechanical properties accessed by nanoindentation tests. Thus, it is expected that the superior integration between nanoparticles and epoxy matrix can enhance the overall performance of the system against underwater corrosion because of the improvement of mechanical properties. In summary, it is envisioned that these nanocomposite coatings can play a crucial role in the future to improve the mechanical properties of FBE systems and concurrently against highly corrosive environments for preventing catastrophic environmental accidents.

\section{Competing Interests}

The authors declare that there is no conflict of interests regarding the publication of this paper.

\section{References}

[1] I. A. Rahman and V. Padavettan, "Synthesis of Silica nanoparticles by sol-gel: size-dependent properties, surface modification, and applications in silica-polymer nanocompositesa review," Journal of Nanomaterials, vol. 2012, Article ID 132424, 15 pages, 2012.

[2] D. R. Paul and L. M. Robeson, "Polymer nanotechnology: nanocomposites," Polymer, vol. 49, no. 15, pp. 3187-3204, 2008.

[3] M. Conradi, "Nanosilica-reinforced polymer composites," Materiali in Tehnologije, vol. 47, no. 3, pp. 285-293, 2013.

[4] T. Mahrholz, J. Stängle, and M. Sinapius, "Quantitation of the reinforcement effect of silica nanoparticles in epoxy resins used in liquid composite moulding processes," Composites Part A: Applied Science and Manufacturing, vol. 40, no. 3, pp. 235-243, 2009.

[5] S. Kango, S. Kalia, A. Celli, J. Njuguna, Y. Habibi, and R. Kumar, "Surface modification of inorganic nanoparticles for development of organic-inorganic nanocomposites-a review," Progress in Polymer Science, vol. 38, no. 8, pp. 1232-1261, 2013.

[6] P. Rostamzadeh, S. M. Mirabedini, and M. Esfandeh, "APSsilane modification of silica nanoparticles: effect of treatment's variables on the grafting content and colloidal stability of the nanoparticles," Journal of Coatings Technology and Research, vol. 11, no. 4, pp. 651-660, 2014.

[7] N. Kavitha, M. Balasubramanian, and A. X. Kennedy, "Investigation of impact behavior of epoxy reinforced with nanometerand micrometer-sized silicon carbide particles," Journal of Composite Materials, vol. 47, no. 15, pp. 1877-1884, 2013.

[8] N. F. Odette and W. Soboyejo, "Failure mechanisms in pipeline epoxy coatings," Advanced Materials Research, vol. 1132, pp. 366-384, 2015.

[9] P. A. Saliba, A. A. Mansur, D. B. Santos, and H. S. Mansur, "Fusion-bonded epoxy composite coatings on chemically functionalized API steel surfaces for potential deep-water petroleum exploration," Applied Adhesion Science, vol. 3, no. 1, article 22, 2015.
[10] T. Nguyen and J. W. Martin, "Modes and mechanisms for the degradation of fusion-bonded epoxy-coated steel in a marine concrete environment," Journal of Coatings Technology and Research, vol. 1, no. 2, pp. 81-92, 2004.

[11] A. Husain, S. Al-Bahar, J. Chakkamalayath et al., "Differential scanning calorimetry and optical photo microscopy examination for the analysis of failure of fusion bonded powder epoxy internal coating," Engineering Failure Analysis, vol. 56, pp. 375383, 2015.

[12] M. R. T. Diodjo, L. Belec, E. Aragon et al., "Silane coupling agent for attaching fusion-bonded epoxy to steel," ACS Applied Materials and Interfaces, vol. 5, no. 14, pp. 6751-6761, 2013.

[13] L. B. Capeletti, L. F. De Oliveira, K. D. A. Gonçalves et al., "Tailored silica-antibiotic nanoparticles: overcoming bacterial resistance with low cytotoxicity," Langmuir, vol. 30, no. 25, pp. 7456-7464, 2014.

[14] American Society for Testing and Materials-ASTM E135608:2014, Standard Test Method for Assignment of the Glass Transition Temperatures by Differential Scanning Calorimetry, ASTM International, Conshohocken, Pa, USA, 2014.

[15] W. C. Oliver and G. M. Pharr, "Improved technique for determining hardness and elastic modulus using load and displacement sensing indentation experiments," Journal of Materials Research, vol. 7, no. 6, pp. 1564-1580, 1992.

[16] M. E. Marques, A. A. P. Mansur, and H. S. Mansur, "Chemical functionalization of surfaces for building three-dimensional engineered biosensors," Applied Surface Science, vol. 275, pp. 347-360, 2013.

[17] Z. Wu, H. Xiang, T. Kim, M.-S. Chun, and K. Lee, "Surface properties of submicrometer silica spheres modified with aminopropyltriethoxysilane and phenyltriethoxysilane," Journal of Colloid and Interface Science, vol. 304, no. 1, pp. 119-124, 2006.

[18] A. Pramanik, K. Bhattacharjee, M. K. Mitra et al., "A mechanistic study of the initial stage of the sintering of sol-gel derived silica nanoparticle," International Journal of Modern Engineering Research, vol. 3, no. 2, pp. 1066-1070, 2013.

[19] M. Jafarzadeh, I. A. Rahman, and C. S. Sipaut, "Synthesis of silica nanoparticles by modified sol-gel process: the effect of mixing modes of the reactants and drying techniques," Journal of Sol-Gel Science and Technology, vol. 50, no. 3, pp. 328-336, 2009.

[20] A. Romero-Pérez, E. García-García, A. Zavaleta-Mancera et al., "Designing and evaluation of sodium selenite nanoparticles in vitro to improve selenium absorption in ruminants," Veterinary Research Communications, vol. 34, no. 1, pp. 71-79, 2010.

[21] M. G. González, J. C. Cabanelas, and J. Baselga, "Applications of FTIR on epoxy resins-identification, monitoring the curing process, phase separation and water uptake," in Infrared Spectroscopy-Materials Science, Engineering and Technology, T. Theophanides, Ed., chapter 13, pp. 261-284, InTech, Rijeka, Croatia, 2012.

[22] M. D. Gilbert, N. S. Schneider, and W. J. MacKnight, "Mechanism of the dicyandiamide/epoxide reaction," Macromolecules, vol. 24, no. 2, pp. 360-369, 1991.

[23] D. Fata and W. Possart, "Aging behavior of a hot-cured epoxy system," Journal of Applied Polymer Science, vol. 99, no. 5, pp. 2726-2736, 2006.

[24] D. Tzetzis, G. Mansour, I. Tsiafis, and E. Pavlidou, "Nanoindentation measurements of fumed silica epoxy reinforced nanocomposites," Journal of Reinforced Plastics and Composites, vol. 32, no. 3, pp. 163-173, 2013. 
[25] H. Furukawa and H. Kanai, "Influence of volatile elements on bubble defect (popping) of thermal hardening type-polyester resin paint film heated on steel sheet," Tetsu-to-Hagané, vol. 99, no. 4, pp. 288-293, 2013.

[26] U. Anjaneyulu and S. Sasikumar, "Bioactive nanocrystalline wollastonite synthesized by sol-gel combustion method by using eggshell waste as calcium source," Bulletin of Materials Science, vol. 37, no. 2, pp. 207-212, 2014.

[27] N. T. Nolan, M. K. Seery, and S. C. Pillai, "Spectroscopic investigation of the anatase-to-rutile transformation of sol-gelsynthesized $\mathrm{TiO}_{2}$ photocatalysts," Journal of Physical Chemistry C, vol. 113, no. 36, pp. 16151-16157, 2009.

[28] R. Hardis, Cure kinetics characterization and monitoring of an epoxy resin for thick composite structures [Graduate Theses and Dissertations], Paper 12608, 2012.

[29] H. Ribeiro, W. M. Silva, M.-T. F. Rodrigues et al., "Glass transition improvement in epoxy/graphene composites," Journal of Materials Science, vol. 48, no. 22, pp. 7883-7892, 2013.

[30] D. Li, "Fracture thoughness measurement using nanoindentation," pp. 1-8, 2014, http://www.nanovea.com/App-Notes/nanofracturetoughness.pdf.

[31] M. Sebastiani, K. E. Johanns, E. G. Herbert, and G. M. Pharr, "Measurement of fracture toughness by nanoindentation methods: recent advances and future challenges," Current Opinion in Solid State and Materials Science, vol. 19, no. 6, pp. 324-333, 2015.

[32] D. Tzetzis and G. Mansour, "Nanoindentation, compression and fractural characterization of highly dispersed epoxy silica nanocomposites," Journal of Reinforced Plastics and Composites, vol. 35, no. 7, pp. 541-555, 2016.

[33] W.-G. Ji, J.-M. Hu, L. Liu, J.-Q. Zhang, and C.-N. Cao, "Water uptake of epoxy coatings modified with $\gamma$-APS silane monomer," Progress in Organic Coatings, vol. 57, no. 4, pp. 439443, 2006.

[34] X. Shi, T. A. Nguyen, Z. Suo, Y. Liu, and R. Avci, "Effect of nanoparticles on the anticorrosion and mechanical properties of epoxy coating," Surface \& Coatings Technology, vol. 204, no. 3, pp. 237-245, 2009. 

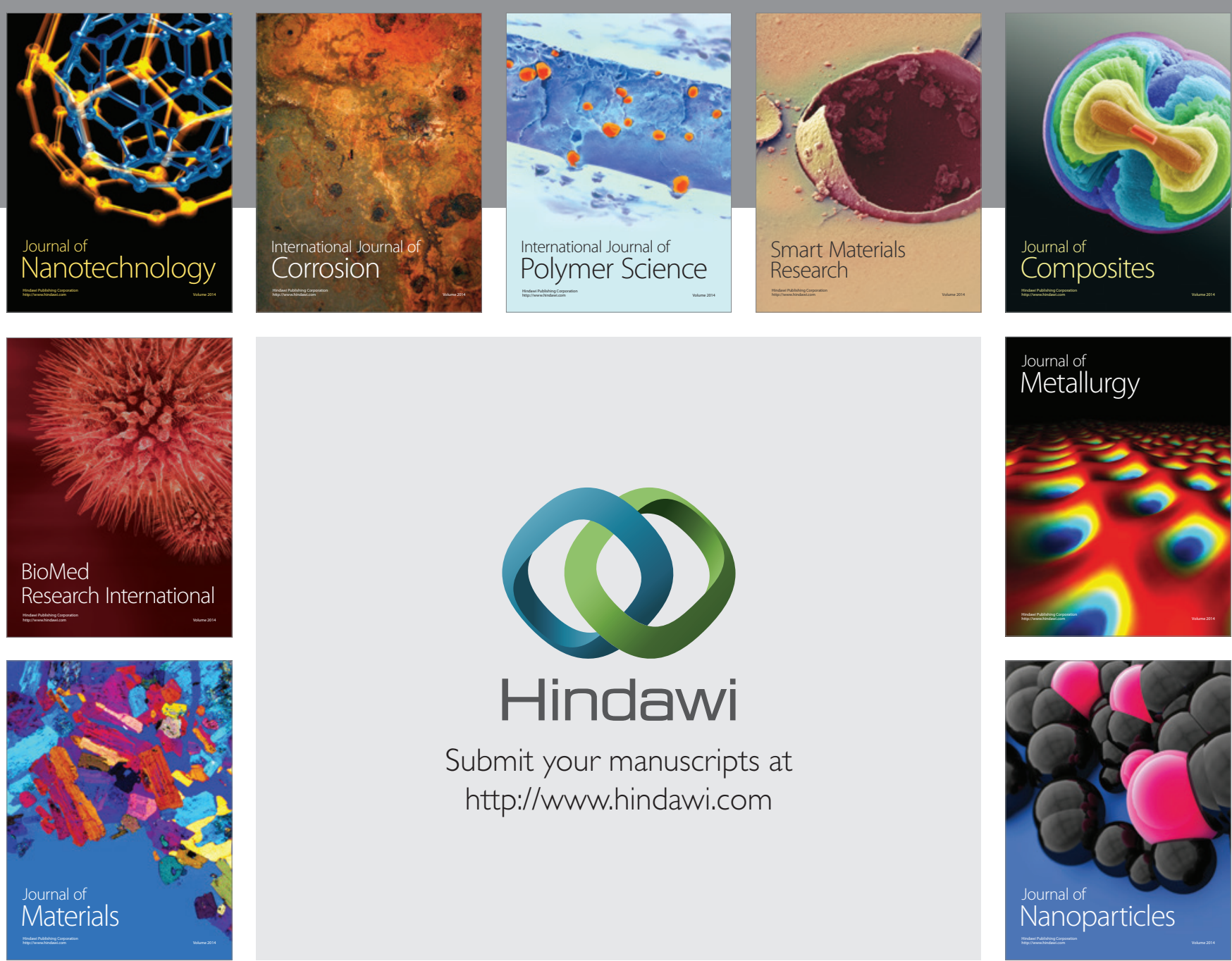

\section{Hindawi}

Submit your manuscripts at

http://www.hindawi.com

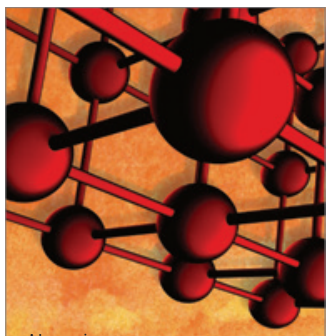

Materials Science and Engineering
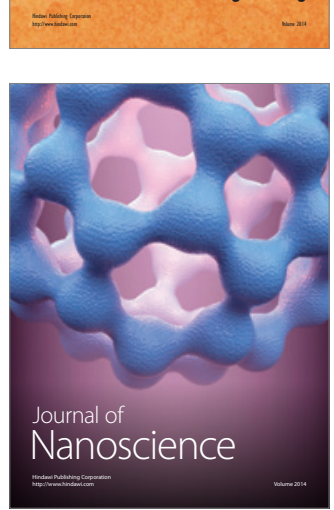
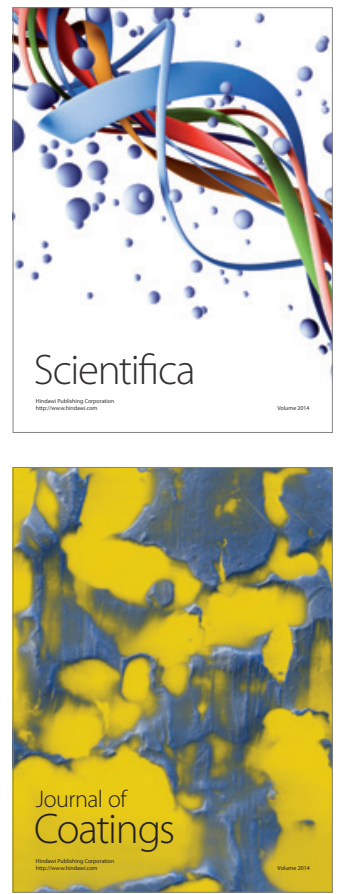
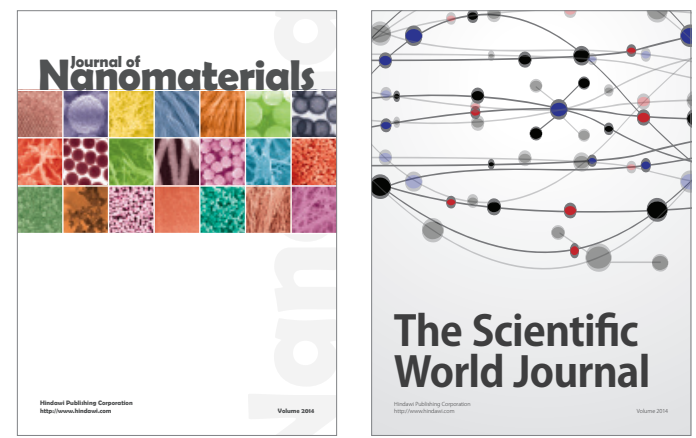

The Scientific World Journal
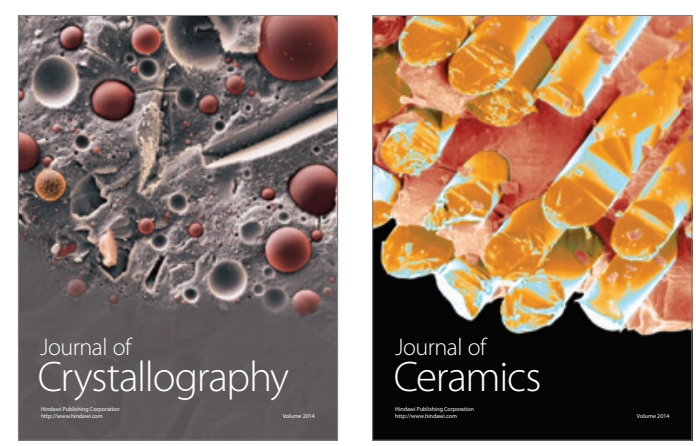
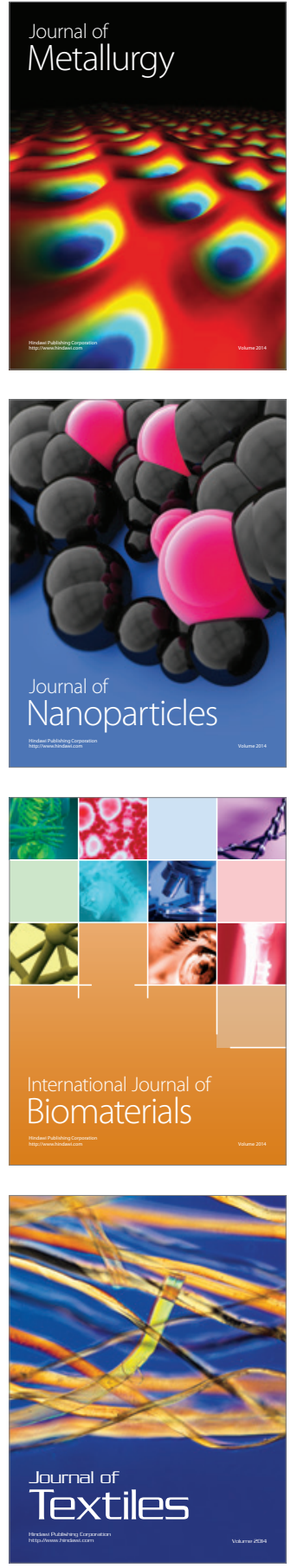